\title{
2-(Dibenzylamino)butane-1,4-Dithiol (DABDT), A Friendly Disulfide Reducing Reagent Compatible with a Broad Range of Solvents
}

\author{
Sinenhlanhla N. Mthembu, ${ }^{1,4}$ Anamika Sharma, ${ }^{1,4}$ Fernando Albericio, ${ }^{1,2,3}$ Beatriz G. \\ de la Torre ${ }^{4}$ \\ ${ }^{1}$ Peptide Science Laboratory, School of Chemistry and Physics, University of KwaZulu-Natal, \\ Durban 4001, South Africa \\ ${ }^{2}$ Department of Organic Chemistry, University of Barcelona, Martí i Franqués 1-11, Barcelona \\ 08028, Spain \\ ${ }^{3}$ CIBER-BBN, Networking Centre on Bioengineering, Biomaterials and Nanomedicine, and \\ IQAC, CSIC, Jordi Girona, Barcelona 08028, Spain \\ ${ }^{4}$ KRISP, College of Health Sciences, University of KwaZulu-Natal, Westville, Durban 4001, \\ South Africa
}

\section{General}

All reagents and solvents were purchased from commercial suppliers and were used without further purification, unless otherwise stated. NMR spectra ( ${ }^{1} \mathrm{H}$ NMR and ${ }^{13} \mathrm{C}$ NMR) were recorded on a Bruker AVANCE III $400 \mathrm{MHz}$ spectrometer. Chemical shift values are expressed in parts per million (ppm). Analytical HPLC was performed on Agilent 1100 system using Phenomenex $\mathrm{C}_{18}$ column $(3 \mu \mathrm{m}, 4.6 \times 50$ $\mathrm{mm})$, and Chemstation software was used for data processing over a 5-95\% gradient of $\mathrm{CH}_{3} \mathrm{CN}(0.1 \%$ TFA)/ $\mathrm{H}_{2} \mathrm{O}(0.1 \%$ TFA) over $15 \mathrm{~min}$, flow rate: $1.0 \mathrm{~mL} / \mathrm{min}$, detection at $220 \mathrm{~nm}$. High resolution mass spectrometry (HRMS) was performed using a Bruker ESI-QTOF mass spectrometer in positive-ion mode.

\section{Experimental}

Synthesis of dibenzyl N,N-dibenzylaspartate (2)

To a solution of $\mathrm{K}_{2} \mathrm{CO}_{3}(4.8 \mathrm{~g} ; 35 \mathrm{mmol})$ in water, aspartic acid ( $\left.1 \mathrm{~g}, 7.5 \mathrm{mmol}\right)$ was added and the reaction was stirred vigorously. Benzyl bromide $(4.1 \mathrm{~mL}, 35 \mathrm{mmol})$ was added dropwise to the above stirring solution. The reaction was stirred at $80{ }^{\circ} \mathrm{C}$ for 40 mins under MW conditions in a sealed reaction vessel (Manufacturer: CEM and Model: Discover SP). The reaction was monitored by TLC until consumption of aspartic acid (as checked by ninhydrin spray). After the complete consumption of aspartic acid, the crude product was extracted with ethyl acetate. Organic layer was washed with water, collected and dried over 
magnesium sulphate. Organic layer was filtered and concentrated to afford crude product which was purified using silica gel column chromatography using $n$-Hexane/Ethyl acetate as mobile phase. The pure product was used for next step.

Pale yellow liquid, yield $=3.4 \mathrm{~g}(94.4 \%)$; HPLC $t_{R}=13.5 \mathrm{~min} ;{ }^{1} \mathrm{H}$ NMR (400 MHz, $\left.\mathrm{CD}_{3} \mathrm{OD}\right): 2.56(\mathrm{dd}, J$ $=7.7 \mathrm{~Hz}, 1 \mathrm{H}), 2.74(\mathrm{dd}, J=7.9 \mathrm{~Hz}, 1 \mathrm{H}), 3.36(\mathrm{~d}, J=13.5 \mathrm{~Hz}, 2 \mathrm{H}), 3.58(\mathrm{~d}, J=13.5 \mathrm{~Hz}, 2 \mathrm{H}), 3.78(\mathrm{t}, J=$ $7.5 \mathrm{~Hz}, 1 \mathrm{H}), 4.78(\mathrm{~d}, J=12.0 \mathrm{~Hz}, 1 \mathrm{H}), 4.95(\mathrm{dd}, J=7.5 \mathrm{~Hz}, 2 \mathrm{H}), 5.10(\mathrm{~d}, J=11.7 \mathrm{~Hz}, 1 \mathrm{H}), 7.05-7.27$ (m, $\mathrm{ArH}) ;{ }^{13} \mathrm{C}$ NMR (100 MHz, $\left.\mathrm{CD}_{3} \mathrm{OD}\right): 35.7,55.8,59.4,67.5,67.6,128.3,129.2$, 129.3, 129.4, 129.5, 129.7, 129.8, 130.0, 137.3, 137.5, 140.3, 172.5, 172.7. HRMS: m/z: calcd. for $\mathrm{C}_{32} \mathrm{H}_{31} \mathrm{NO}_{4}: 494.2325[\mathrm{M}+\mathrm{H}]^{+}$; found: 494.2348 .

Synthesis of 2-(dibenzylamino)butane-1,4-diol (3)

Cooled a solution of $2(3.2 \mathrm{~g}, 6.5 \mathrm{mmol})$ in diethyl ether and stirred vigorously. To the ice cooled stirring solution added $\mathrm{LAH}$ in three portions and then the reaction was stirred for $4 \mathrm{~h}$ at room temperature. The reaction was monitored by TLC until complete consumption of $\mathbf{2}$. After completion, excess LAH was quenched using water maintaining the temperature at $0{ }^{\circ} \mathrm{C}$. The suspension was filtered to remove the salts. The aqueous layer was washed several times with ethyl acetate. Organic layer was collected, dried over magnesium sulphate, filtered and concentrated to afford crude product which was purified using silica gel column chromatography using $n$-Hexane/Ethyl acetate as mobile phase. The pure product was used for next step.

Pale pink semi solid, yield $=1.5 \mathrm{~g}(81 \%) ; \mathrm{HPLC}_{R}=5.9 \mathrm{~min} ;{ }^{1} \mathrm{H} \mathrm{NMR}\left(400 \mathrm{MHz}, \mathrm{CD}_{3} \mathrm{OD}\right): 1.59(\mathrm{~m}, 1 \mathrm{H})$, $1.92(\mathrm{~m}, 1 \mathrm{H}), 2.87(\mathrm{~m}, 1 \mathrm{H}), 3.52-3.76(\mathrm{~m}, 8 \mathrm{H}), 7.18-7.33(\mathrm{~m}, \mathrm{ArH}) ;{ }^{13} \mathrm{C} \mathrm{NMR}\left(100 \mathrm{MHz}, \mathrm{CD}_{3} \mathrm{OD}\right): 31.5$, 54.9, 58.6, 62.0, 62.6, 128.2, 129.4, 130.2, 141.3. HRMS: m/z: calcd. for $\mathrm{C}_{18} \mathrm{H}_{23} \mathrm{NO}_{2}: 286.1801[\mathrm{M}+\mathrm{H}]^{+}$; found: 286.1811 .

Synthesis of $S, S^{\prime}-(2-($ dibenzylamino)butane-1,4-diyl) diethanethioate (4)

3 (1.5 g, $5.3 \mathrm{mmol}$ ) was dissolved in DCM and $\mathrm{SOCl}_{2}$ was added in excess. The reaction was stirred at 60 ${ }^{\circ} \mathrm{C}$ using oil bath and was monitored by TLC until no starting material was observed. After $3 \mathrm{~h}$ solvent was removed completely, and crude was used directly for next step. The residue was dissolved in ACN and a solution of potassium thioacetate (5 eq) in ACN with few drops of DMF (for solubility) was added followed by triethyl amine $(75 \mu \mathrm{L}, 0.1 \mathrm{mmol})$. The reaction was further heated to $60{ }^{\circ} \mathrm{C}$ using oil bath and was monitored by TLC for consumption of SM. After $4 \mathrm{~h}$ when no starting material was observed (as monitored by TLC), the solvent was removed under vacuum. The crude was washed with water and extracted with ethyl acetate. Organic layer was collected, dried over magnesium sulphate, filtered and concentrated to 
afford crude product which was purified using silica gel column chromatography using $n$-Hexane/Ethyl acetate as mobile phase. The pure product was used for next step.

Dark red semi solid, yield $=1.0 \mathrm{~g}(67 \%)$; HPLC $t_{R}=10.1 \mathrm{~min} ;{ }^{1} \mathrm{H}$ NMR $\left(400 \mathrm{MHz}, \mathrm{CDCl}_{3}\right): 1.53(\mathrm{~m}, 1 \mathrm{H})$, $1.82(\mathrm{~m}, 1 \mathrm{H}), 2.18(\mathrm{~s}, 3 \mathrm{H}), 2.22(\mathrm{~s}, 3 \mathrm{H}), 2.63(\mathrm{~m}, 2 \mathrm{H}), 2.76(\mathrm{~m}, 1 \mathrm{H}), 2.99(\mathrm{~m}, 1 \mathrm{H}), 3.19(\mathrm{~m}, 1 \mathrm{H}), 3.51(\mathrm{~d}, J$ $=13.5 \mathrm{~Hz}, 2 \mathrm{H}), 3.59$ (d, $J=13.9 \mathrm{~Hz}, 2 \mathrm{H}), 7.14-7.29(\mathrm{~m}, \mathrm{ArH}) ;{ }^{13} \mathrm{C} \mathrm{NMR}\left(100 \mathrm{MHz}, \mathrm{CDCl}_{3}\right)$ : 25.7, 27.9, 29.1, 29.6, 52.2, 56.1, 125.9, 127.2, 128.0, 138.5, 194.4, 194.8. HRMS: m/z: calcd. for $\mathrm{C}_{22} \mathrm{H}_{27} \mathrm{NO}_{2} \mathrm{~S}_{2}$ : $402.1556[\mathrm{M}+\mathrm{H}]^{+}$; found: 402.1568 .

Synthesis of 2-(dibenzylamino)butane-1,4-dithiol (1)

Method I: Using LR

3 (50 mg, $0.2 \mathrm{mmol}$ ) was dissolved in toluene and LR (121 mg, $0.3 \mathrm{mmol})$ was added. The reaction was heated for $12 \mathrm{~h}$ (conventional) or $2 \mathrm{~h}$ (MW as above) at $140{ }^{\circ} \mathrm{C}$. Solvent was removed under vacuum. No product formation.

Method II: Using thiourea

3 (50 mg, $0.2 \mathrm{mmol}$ ) was dissolved in DCM and $\mathrm{SOCl}_{2}$ was added in excess. The reaction was stirred at 60 ${ }^{\circ} \mathrm{C}$ using oil bath and was monitored by TLC until no starting material was observed. After $3 \mathrm{~h}$ solvent was removed completely to afford residue which was directly used for the next step. Thiourea and residue was dissolved in EtOH. The reaction was refluxed for $8 \mathrm{~h}$ under nitrogen. To this reaction mixture, $6 \mathrm{~N} \mathrm{NaOH}$ $(2 \mathrm{~mL})$ was added and further refluxed for $2 \mathrm{~h}$. The reaction was cooled to room temperature and $2 \mathrm{~N} \mathrm{HCl}$ was added until pH 4 was obtained followed by extraction with DCM. The organic layer was collected, dried over magnesium sulphate, filtered and concentrated. Only trace amount of desired product was obtained.

Method III: From thioester

Three approaches were made to synthesis DABDT (1) from thioester (4)

Approach IIIa: Using $\mathrm{HCl}$

Compound 4 (50 mg, $0.12 \mathrm{mmol}$ ) was dissolved in $\mathrm{MeOH}$ followed by addition of $5 \mathrm{~mL}$ of 3N HCl. The reaction mixture was heated at $70{ }^{\circ} \mathrm{C}$ in $\mathrm{MW}$ (as above). The reaction was monitored until complete consumption of SM. After $2.5 \mathrm{~h}, \mathrm{MeOH}$ was removed under vacuum and residue was extracted with DCM. The organic layer was collected, dried over magnesium sulphate, filtered and concentrated. The DABDT ${ }^{\text {ox }}$ was also formed along with the desired product. 


\section{Approach IIIb: Using LAH}

LAH was suspended in diethyl ether and compound $4(50 \mathrm{mg}, 0.12 \mathrm{mmol})$ in diethyl ether was added at 0 C. The reaction mixture vigorously stirred at $\mathrm{rt}$ for 10 mins. The reaction was quenched using water followed by addition of conc $\mathrm{HCl}$ to make the reaction mixture acidic. The crude was extracted with DCM. The organic layer was collected, dried over magnesium sulphate, filtered and concentrated affording pure DABDT.

Approach IIIc: Using $\mathrm{NaBH}_{4}$

4 (50 mg, $0.12 \mathrm{mmol}$ ) was dissolved in methanol and $\mathrm{NaBH}_{4}$ was added 10 folds in excess. The reaction was stirred vigorously at $\mathrm{rt}$ for 30 mins. Conc $\mathrm{HCl}$ was added until solution was acidic enough. Crude was washed with water and extracted with DCM. Organic layer was collected, dried over magnesium sulphate, filtered and concentrated to afford pure $\mathbf{1}$.

Yellow solid, yield $=47 \mathrm{mg}(93.0 \%)$; HPLC $t_{R}=8.24 \mathrm{~min} ;{ }^{1} \mathrm{H}$ NMR $\left(400 \mathrm{MHz}, \mathrm{CDCl}_{3}\right): 1.20$ (s, thiol2H), $1.79(\mathrm{~m}, 2 \mathrm{H}), 2.32(\mathrm{~m}, 1 \mathrm{H}), 2.50(\mathrm{~m}, 2 \mathrm{H}), 2.70(\mathrm{~m}, 1 \mathrm{H}), 2.86(\mathrm{~m}, 1 \mathrm{H}), 3.46(\mathrm{~d}, J=13.5 \mathrm{~Hz}, 2 \mathrm{H}), 3.61$ $(\mathrm{d}, J=13.5 \mathrm{~Hz}, 2 \mathrm{H}), 7.16-7.27$ (m, $\mathrm{ArH}) ;{ }^{13} \mathrm{C} \mathrm{NMR}\left(100 \mathrm{MHz}, \mathrm{CDCl}_{3}\right)$ : 21.0, 22.9, 32.9, 52.4, 58.2, 126.1, 127.4, 128.0, 138.4. HRMS: m/z: calcd. for $\mathrm{C}_{18} \mathrm{H}_{23} \mathrm{NS}_{2}: 318.1601[\mathrm{M}+\mathrm{H}]^{+}$; found:318.1601.

Synthesis of $N, N$-dibenzyl-1,2-dithian-4-amine $\left(\mathbf{1}^{\mathbf{o x}}\right)$

$6 \mathrm{~N} \mathrm{NaOH}$ solution $(1 \mathrm{~mL})$ was added to $\mathbf{1}(15 \mathrm{mg})$. Reaction was extracted with DCM. Organic layer was collected, dried over magnesium sulphate, filtered and concentrated to afford pure $\mathbf{1}^{\mathbf{o x}}$.

Yellow solid, yield $=14.5 \mathrm{mg}(97 \%)$, HPLC $t_{R}=7.89 \mathrm{~min} ;{ }^{1} \mathrm{H}$ NMR $\left(400 \mathrm{MHz}, \mathrm{CDCl}_{3}\right): 1.82(\mathrm{~m}, 2 \mathrm{H})$, $2.26(\mathrm{~m}, 1 \mathrm{H}), 2.53(\mathrm{~m}, 1 \mathrm{H}), 2.82(\mathrm{~m}, 2 \mathrm{H}), 2.95(\mathrm{~m}, 1 \mathrm{H}), 3.54(\mathrm{~d}, J=13.9 \mathrm{~Hz}, 2 \mathrm{H}), 3.65(\mathrm{~d}, J=13.9 \mathrm{~Hz}$, 2H), 7.14-7.28 (m, ArH); ${ }^{13} \mathrm{C}$ NMR (100 MHz, $\left.\mathrm{CDCl}_{3}\right): 28.7,34.1,35.6,52.6,56.4,125.9,127.3,127.4$, 138.9. HRMS: $\mathrm{m} / \mathrm{z}$ : calcd. for $\mathrm{C}_{18} \mathrm{H}_{23} \mathrm{NS}_{2}: 316.1188[\mathrm{M}+\mathrm{H}]^{+}$; found: 316.1182 .

\section{General protocol for synthesis of peptide}

Fmoc-Rink-Amide AM resin (0.74 mmol/gram, 1 equiv.) was washed with DMF $(2 \times 1 \mathrm{~min}), \mathrm{CH}_{2} \mathrm{Cl}_{2}(2 \times$ $1 \mathrm{~min})$ and DMF $(2 \times 1 \mathrm{~min})$. Deprotection of the Fmoc group was achieved by treatment of the resin with $20 \%$ piperidine/DMF $(1 \times 1 \mathrm{~min}$ and $1 \times 7 \mathrm{~min})$ followed by washing with $\mathrm{DMF}, \mathrm{CH}_{2} \mathrm{Cl}_{2}$ and DMF. The protected Fmoc-amino acids ( 3 eq.) were incorporated using DIC (3 eq.) and OxymaPure (3 eq.) in DMF, as a coupling system, 30 mins at rt. This was repeated until the final peptide was achieved. Washes between couplings and deprotections were performed with DMF $(3 \times 1 \mathrm{~min}), \mathrm{CH}_{2} \mathrm{Cl}_{2}(3 \times 1 \mathrm{~min})$ and DMF $(3 \times 1$ 
min). After the peptide synthesis, Fmoc was removed from both the peptides. In one case acetylation (acetic anhydride and DIEA in 1:2 ratio using DMF as solvent) was performed for 30 mins. In another case, dithiodipropionic acid (DTDP; 3 eq.) using DIC (3 eq.) and OxymaPure (3 eq.) in DMF for 30 mins. Both the peptides were dried and microcleavage was performed, by treating with TFA/TIS/ $\mathrm{H}_{2} \mathrm{O}(95: 2.5: 2.5)$ for $1 \mathrm{~h}$ at rt. The cleavage mixture was evaporated with a stream of nitrogen, precipitated with $\mathrm{Et}_{2} \mathrm{O}$, centrifuged and the pellet was re-dissolved in $\mathrm{H}_{2} \mathrm{O} / \mathrm{CH}_{3} \mathrm{CN}$ (1:1) for analysis by HPLC and LCMS.

\section{General protocol for study of DABDT as a reducing agent in solution phase for Fmoc-Cys(S-DMP)- OH}

The equimolar solution (10 mmol) of DABDT and Fmoc-Cys(S-DMP)-OH was prepared separately in acetonitrile. Different ratio (1:5, 1:3 and 1:1) of both solutions were mixed for studying the reduction reaction. $5 \mu \mathrm{L}$ of Fmoc-Cys(S-DMP)-OH and $250 \mu \mathrm{L}$ of DABDT (150 $\mu \mathrm{L}$ for $1: 3$ and $5 \mu \mathrm{L}$ for 1:1) and 10 $\mu \mathrm{M}$ DIEA and $3 \%$ water were added and immediately $2 \mu \mathrm{L}$ of sample was injected in HPLC.

\section{General protocol for study of DABDT as a reducing agent in solid phase}

$10 \mathrm{mg}$ of the resin was washed with DMF. $100 \mathrm{mg} / \mathrm{mL}$ solution of DABDT was prepared in DMF. To the washed resin, $50 \mu \mathrm{L}$ of DABDT solution (also attempted at 1:3 and 1:1 ratio) was added with $5 \mu \mathrm{L}$ of DIEA and $1 \mu \mathrm{L}$ water. After 5 mins the supernatant was discarded, and above reaction was repeated twice for 5 mins each. The resin was washed with DMF and DCM and dried. Minicleavage was performed using TFA for 30 mins at each step of addition of DABDT. TFA was evaporated with a stream of nitrogen, precipitated with $\mathrm{Et}_{2} \mathrm{O}$, centrifuged and the pellet was re-dissolved in $\mathrm{H}_{2} \mathrm{O} / \mathrm{CH}_{3} \mathrm{CN}$ (1:1) for analysis by HPLC and LCMS. 


\section{Characterization of Synthesized Molecules}

Figure S1: HPLC for Compound 2

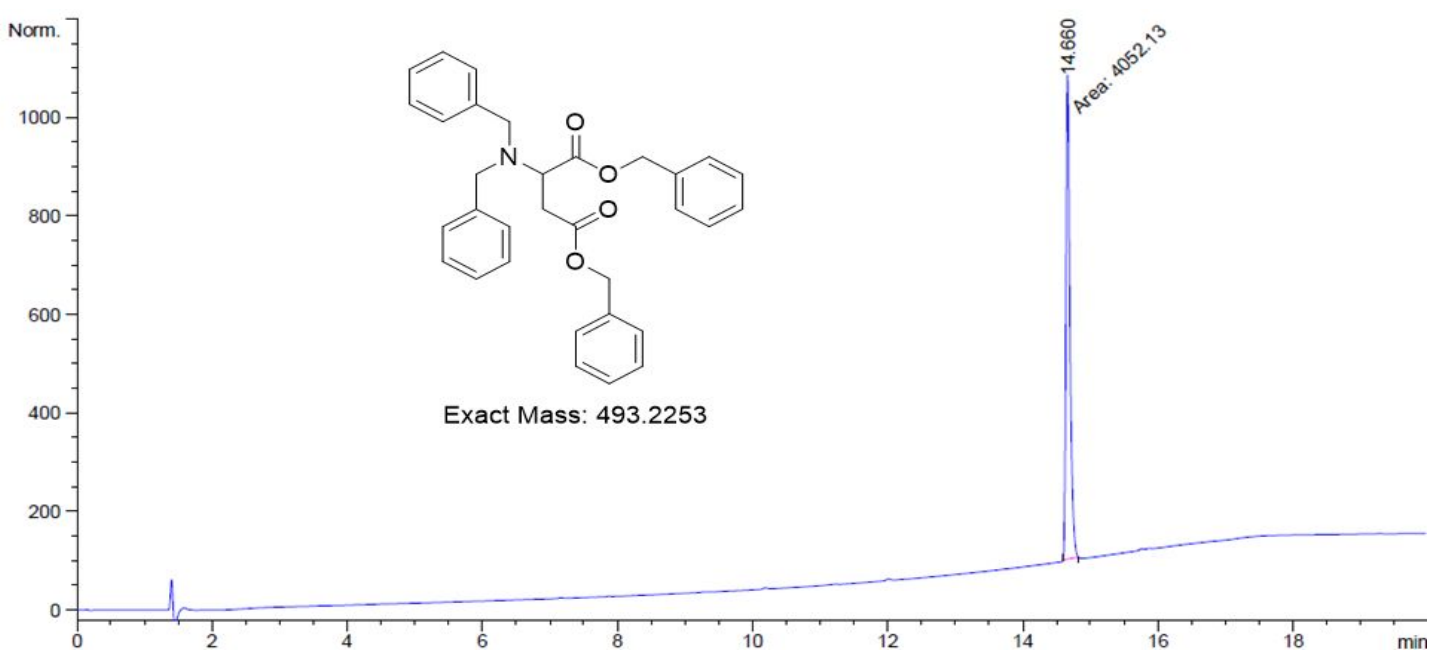

Figure S2: HRMS for Compound 2

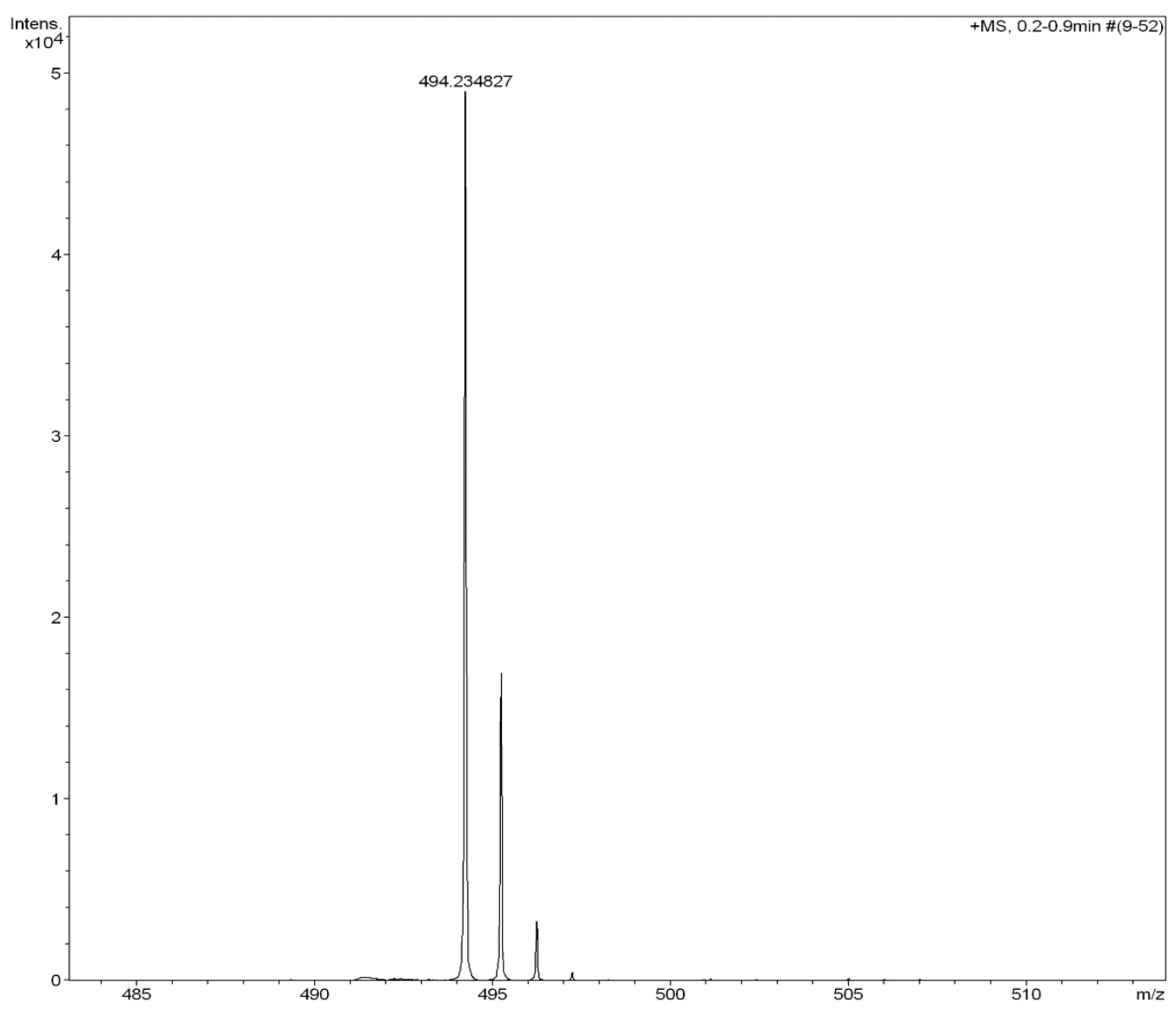


Figure S3. ${ }^{1} \mathrm{H}$ NMR for 2

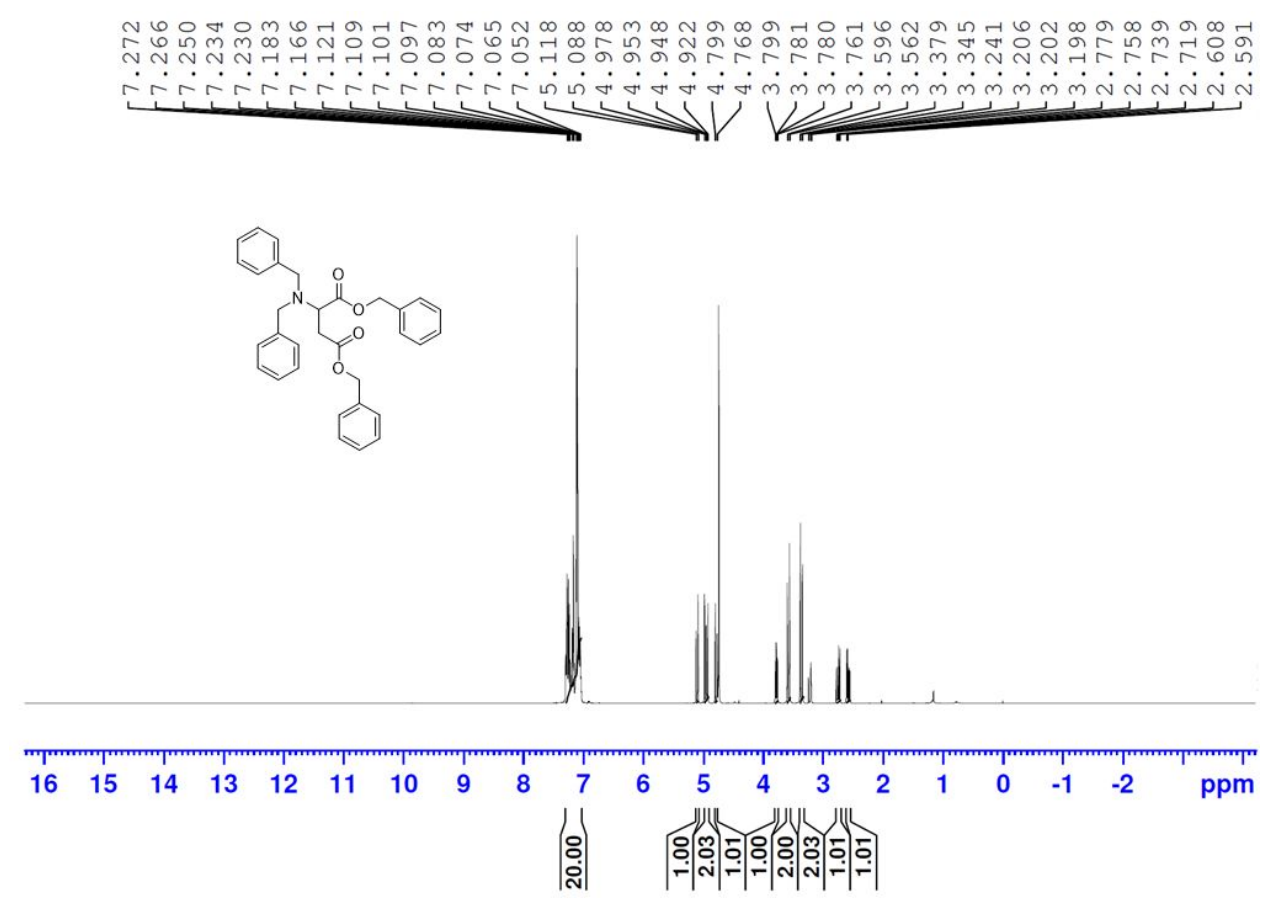

Figure S4. ${ }^{13} \mathrm{C}$ NMR for 2




Figure S5. ${ }^{13} \mathrm{C}$ DEPT 135 for $\mathbf{2}$

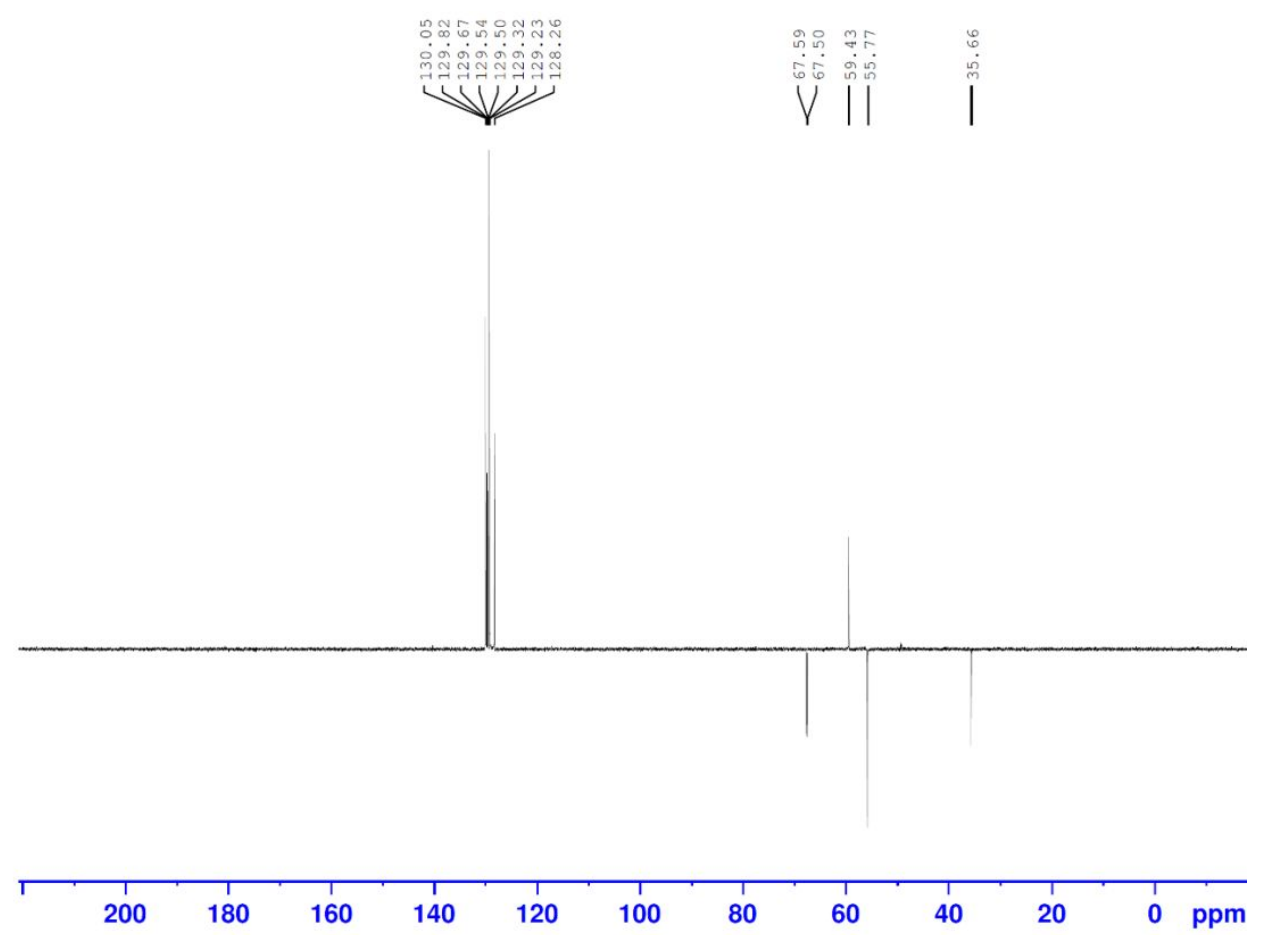

Figure S6. 2D NMR HSQC for 2

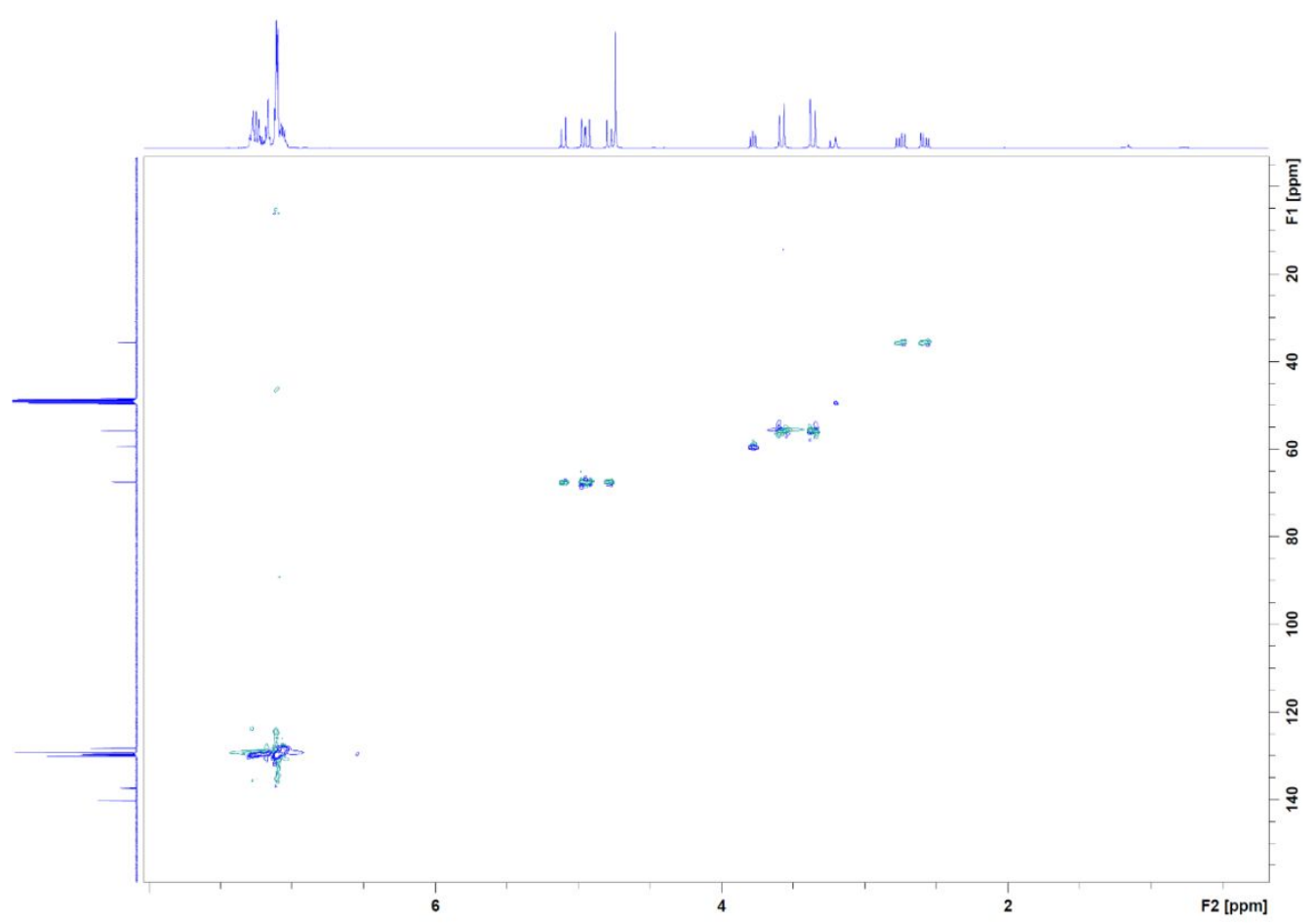


Figure S7. 2D NMR HMBC for 2

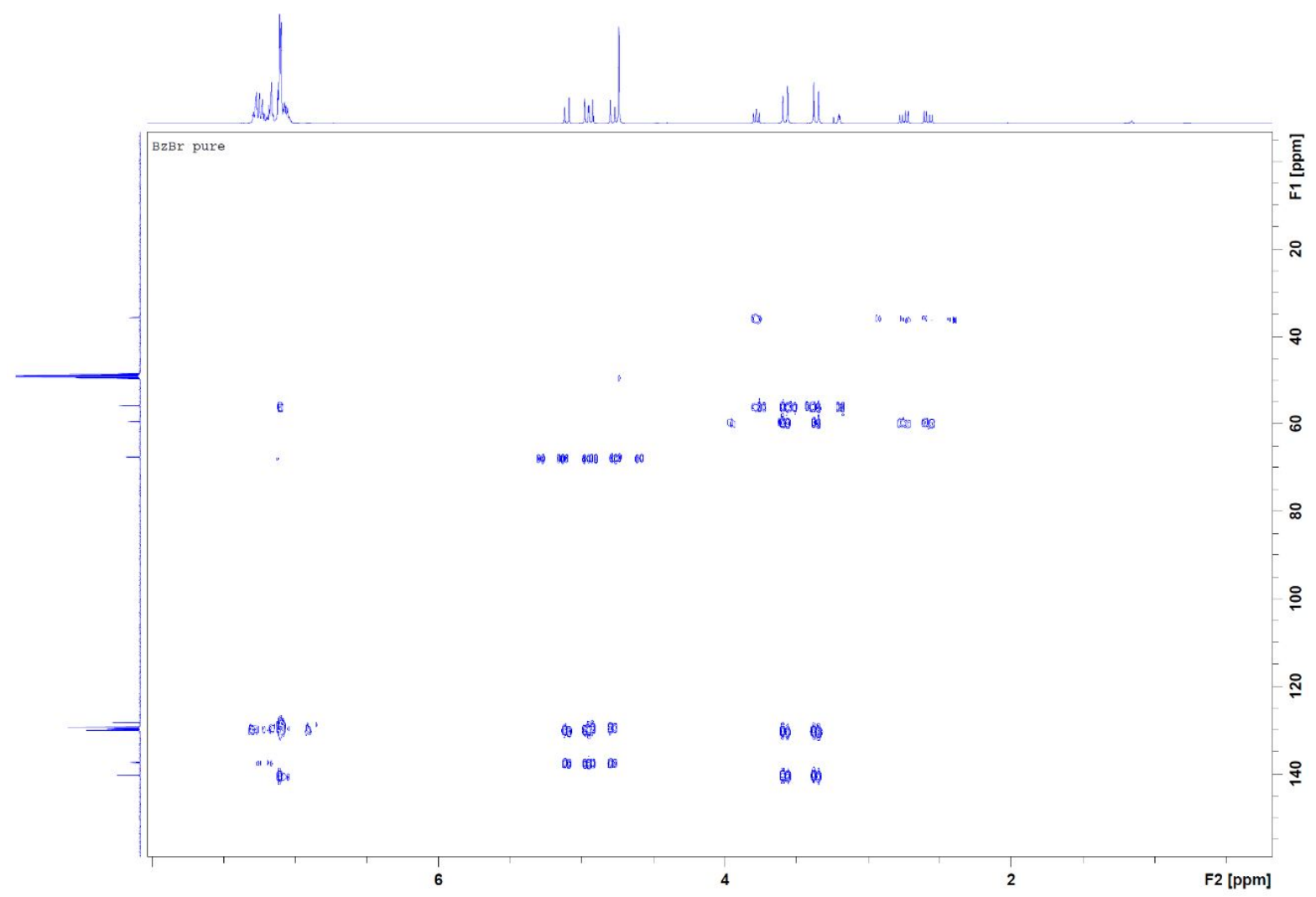

Figure S8: HPLC for Compound 3

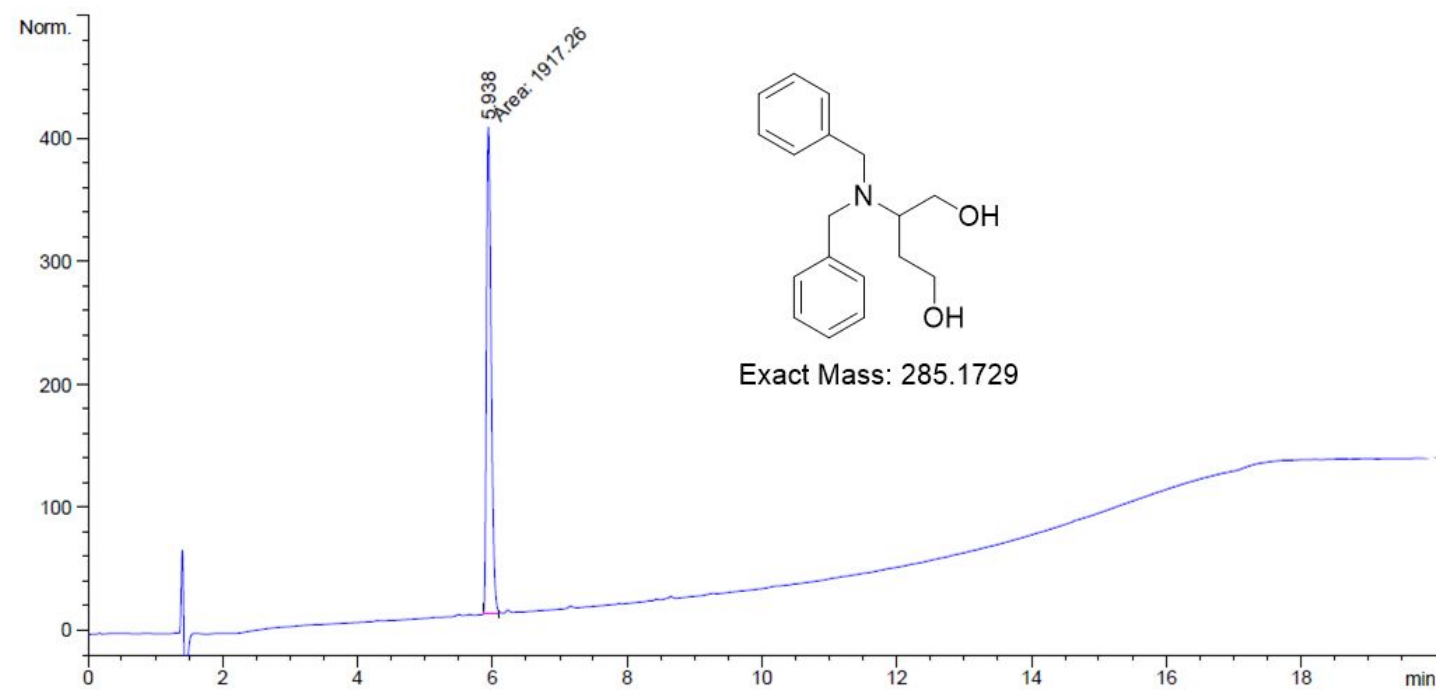


Figure S9: HRMS for compound 3

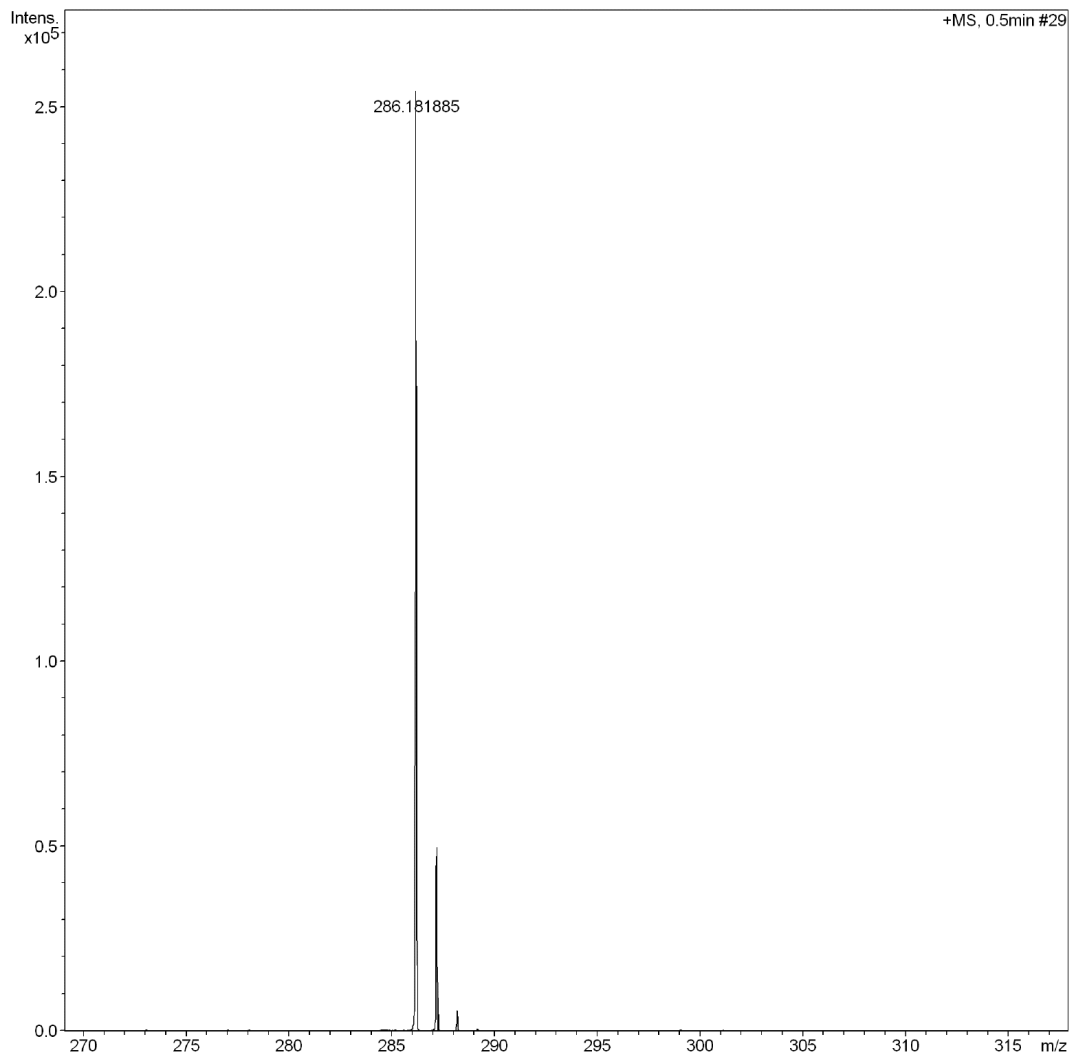

Figure S10. ${ }^{1} \mathrm{H}$ NMR for 3

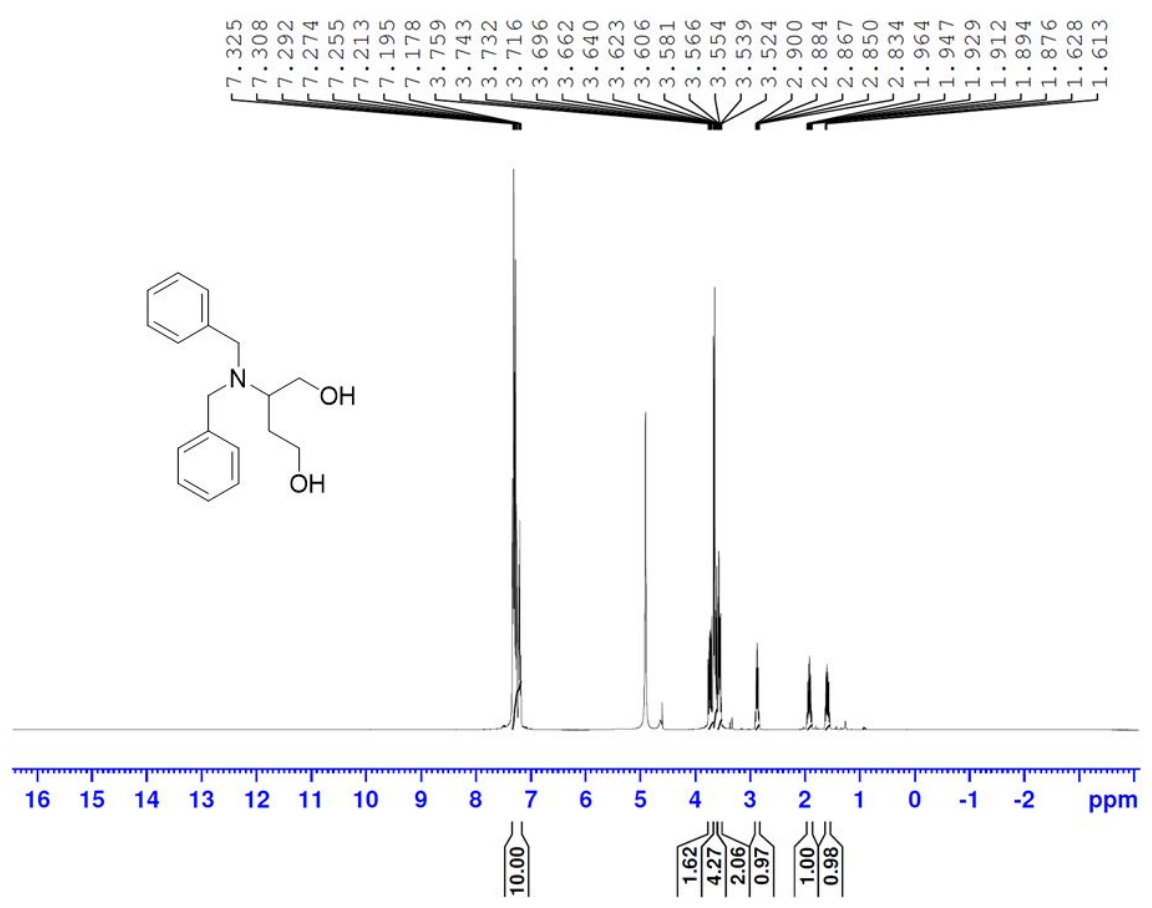


Figure S11. ${ }^{13} \mathrm{C}$ NMR for 3

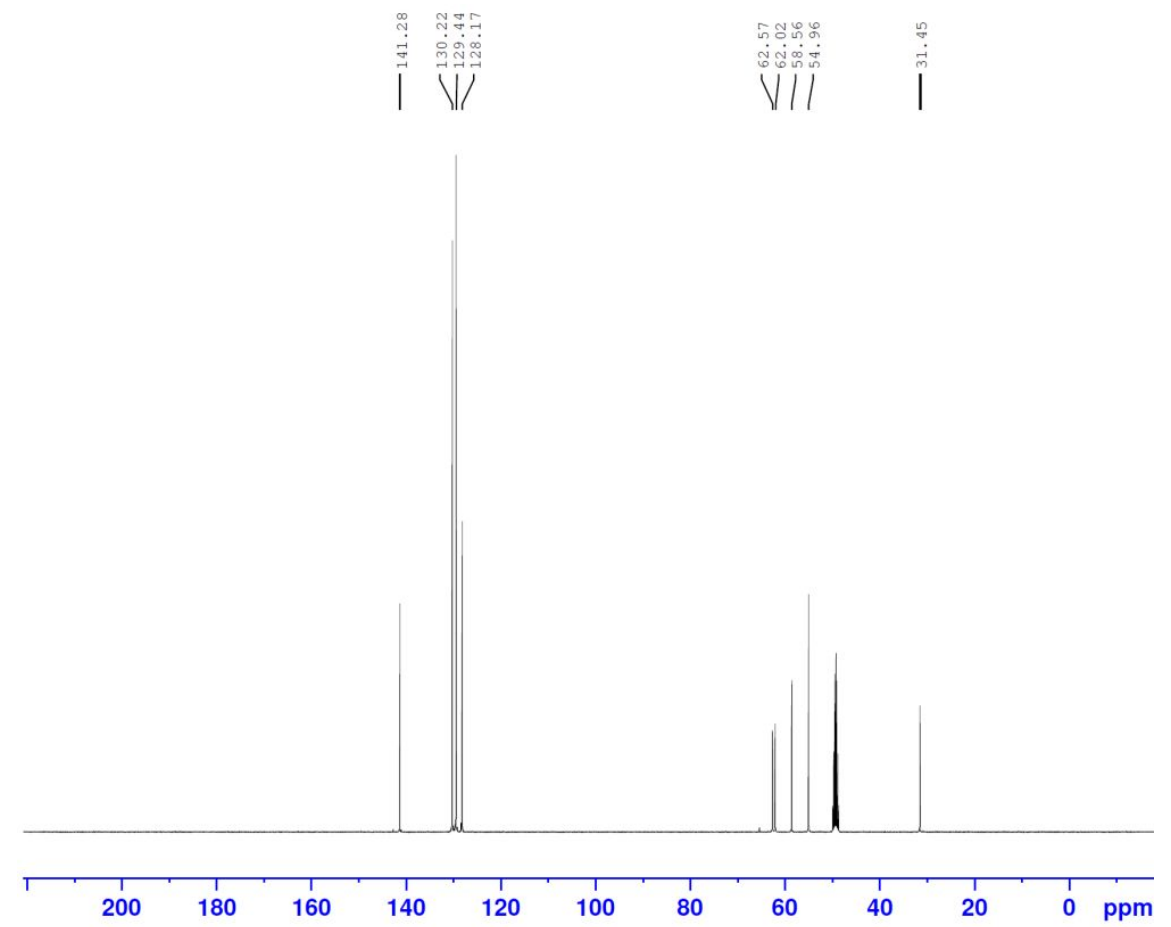

Figure S12. ${ }^{13} \mathrm{C}$ DEPT 135 for 3

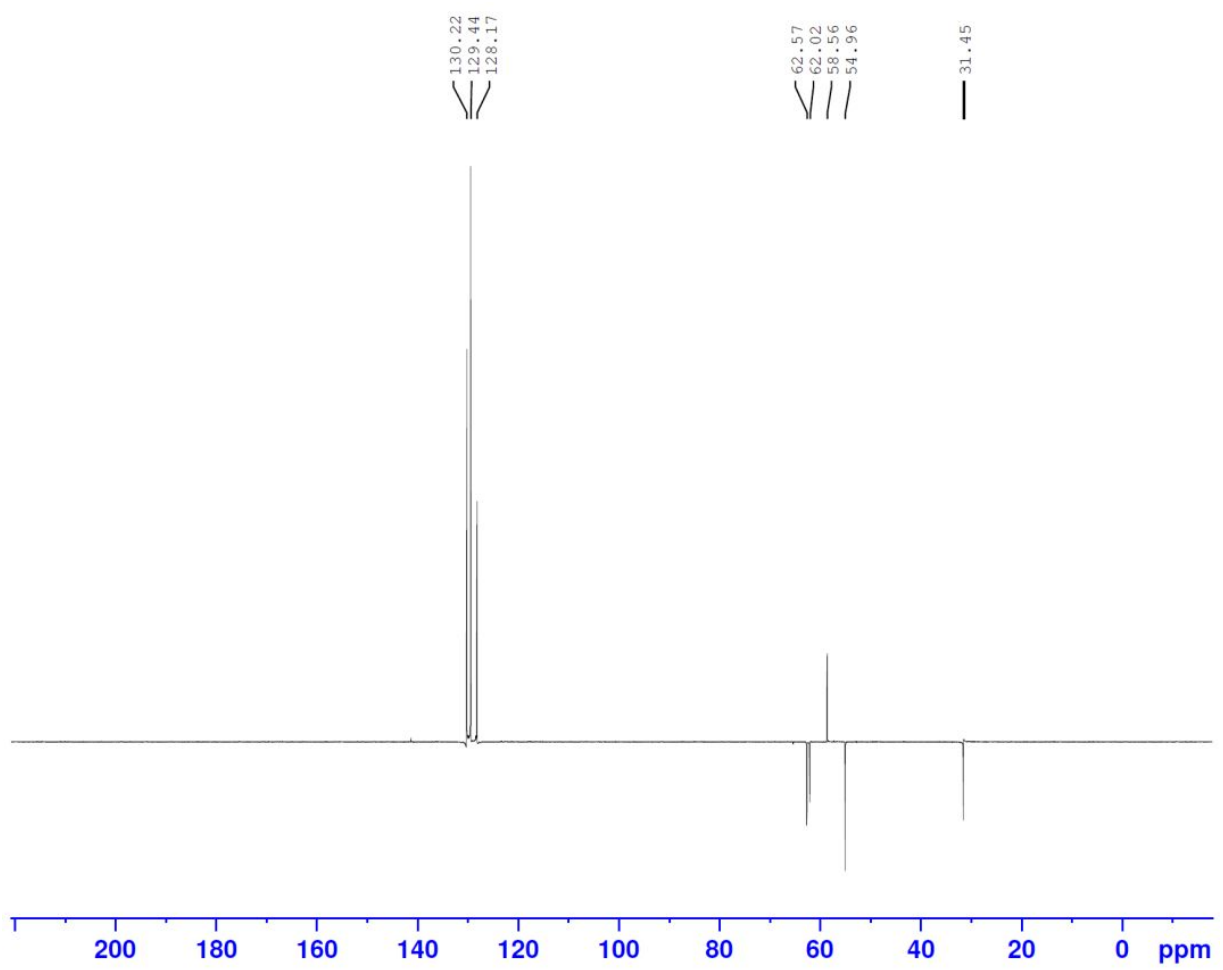


Figure S13. 2D NMR HSQC for 3

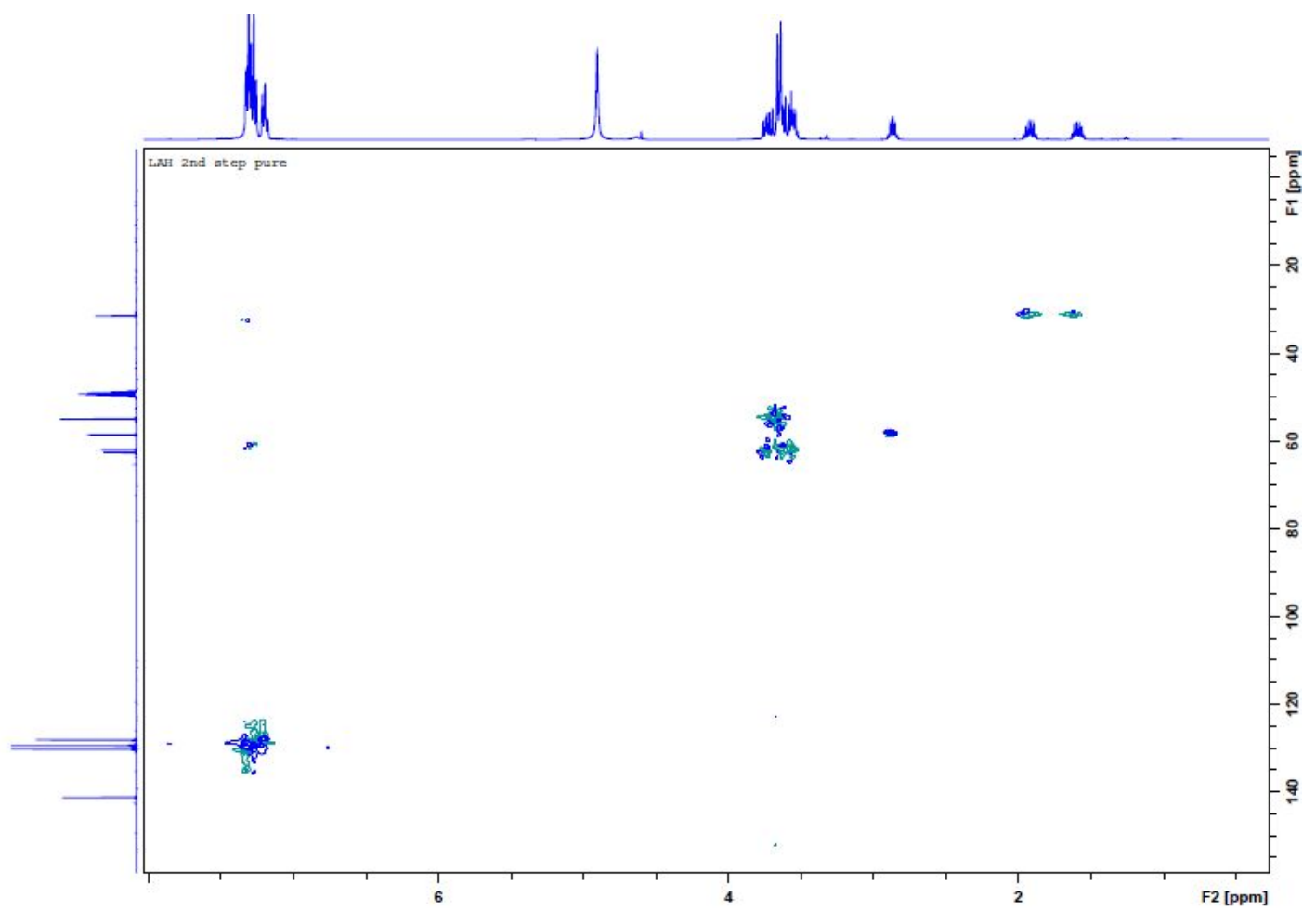

Figure S14. 2D NMR HMBC for 3

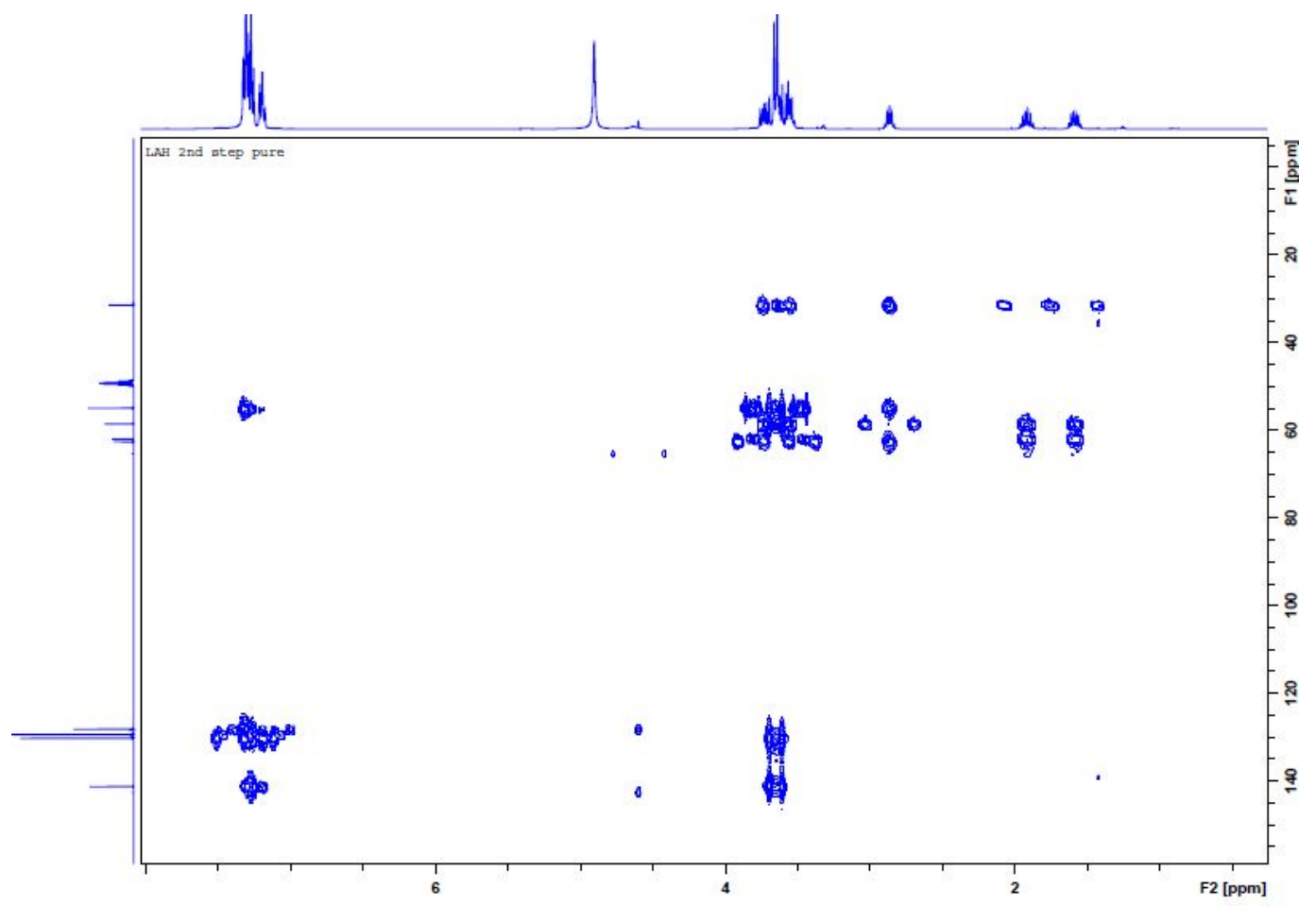


Figure S15: HPLC for Compound 4

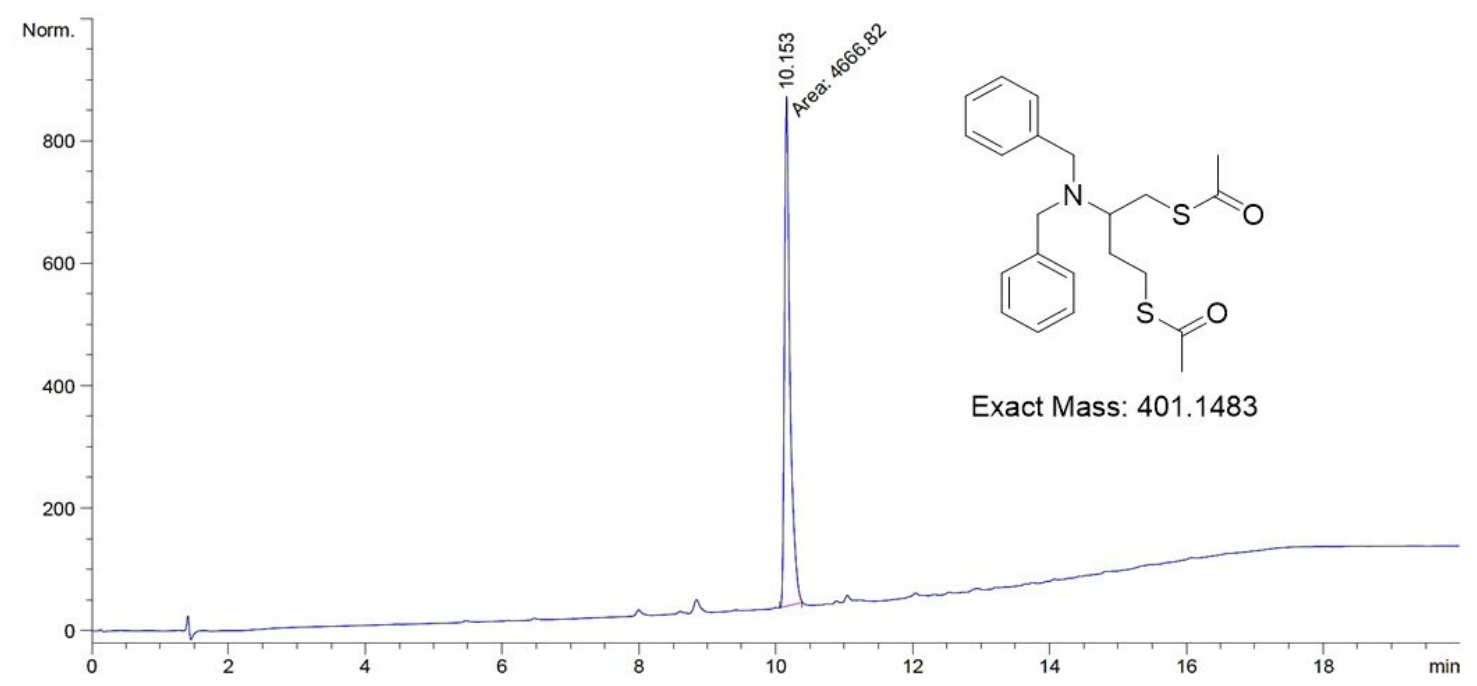

Figure S16: HRMS for compound 4




Figure S17. ${ }^{1} \mathrm{H}$ NMR for 4

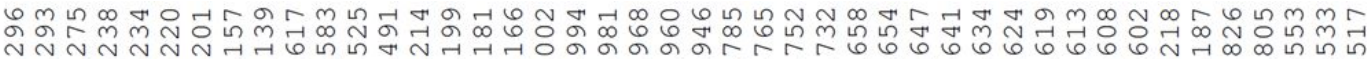

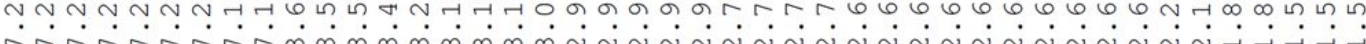

NRNARNRmmmmmmmmm N

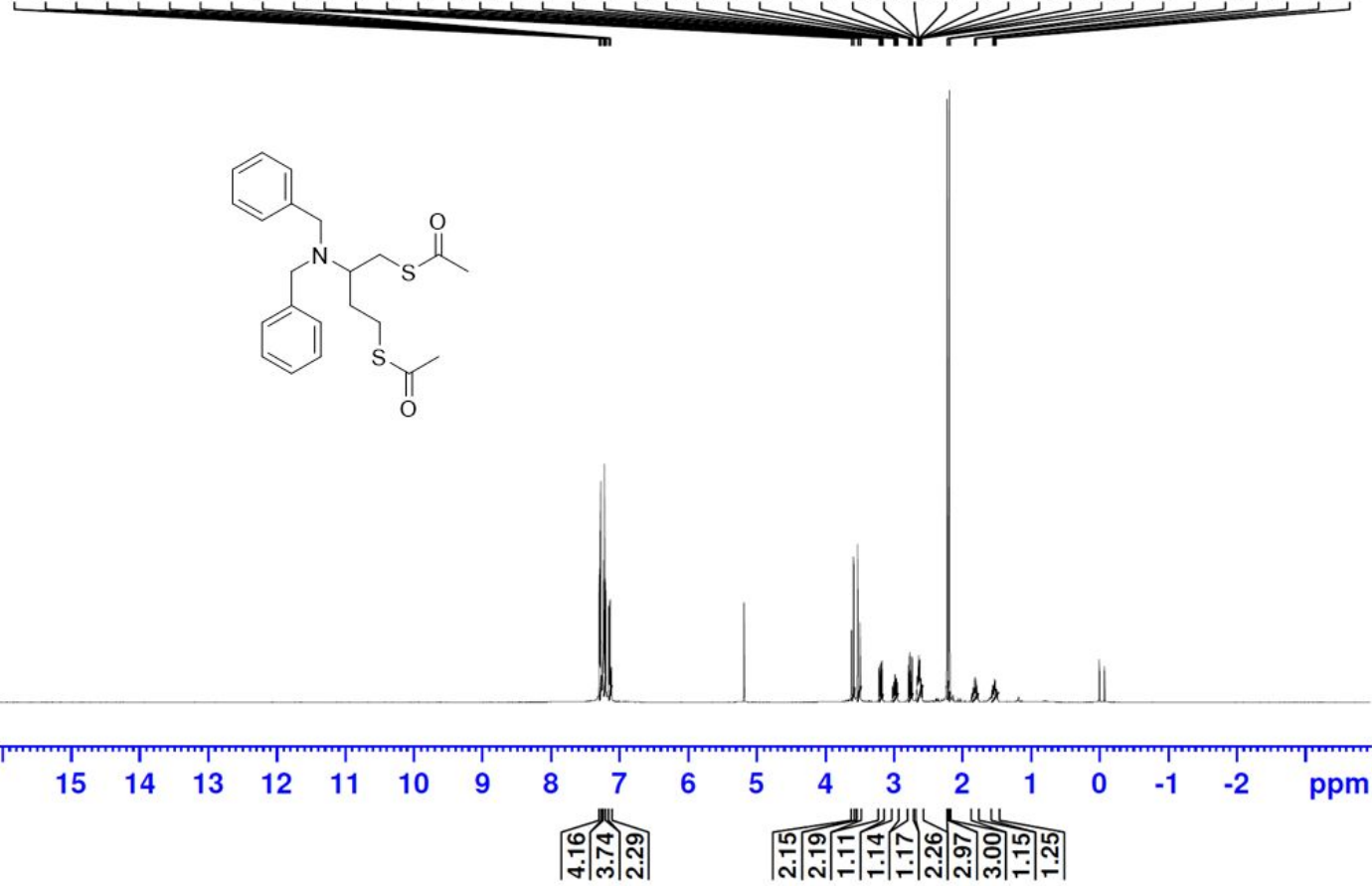

Figure S18. ${ }^{13} \mathrm{C}$ NMR for 4

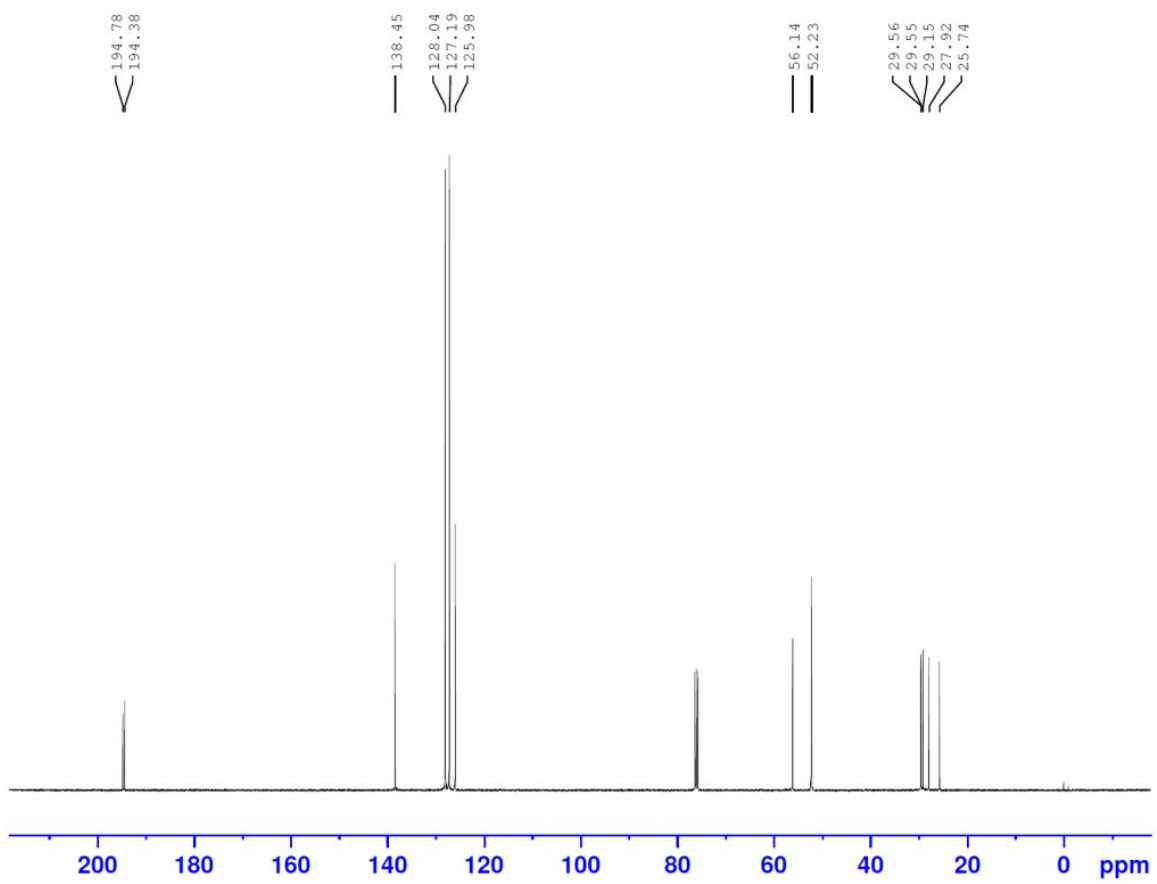


Figure S19. ${ }^{13} \mathrm{C}$ DEPT 135 for $\mathbf{4}$

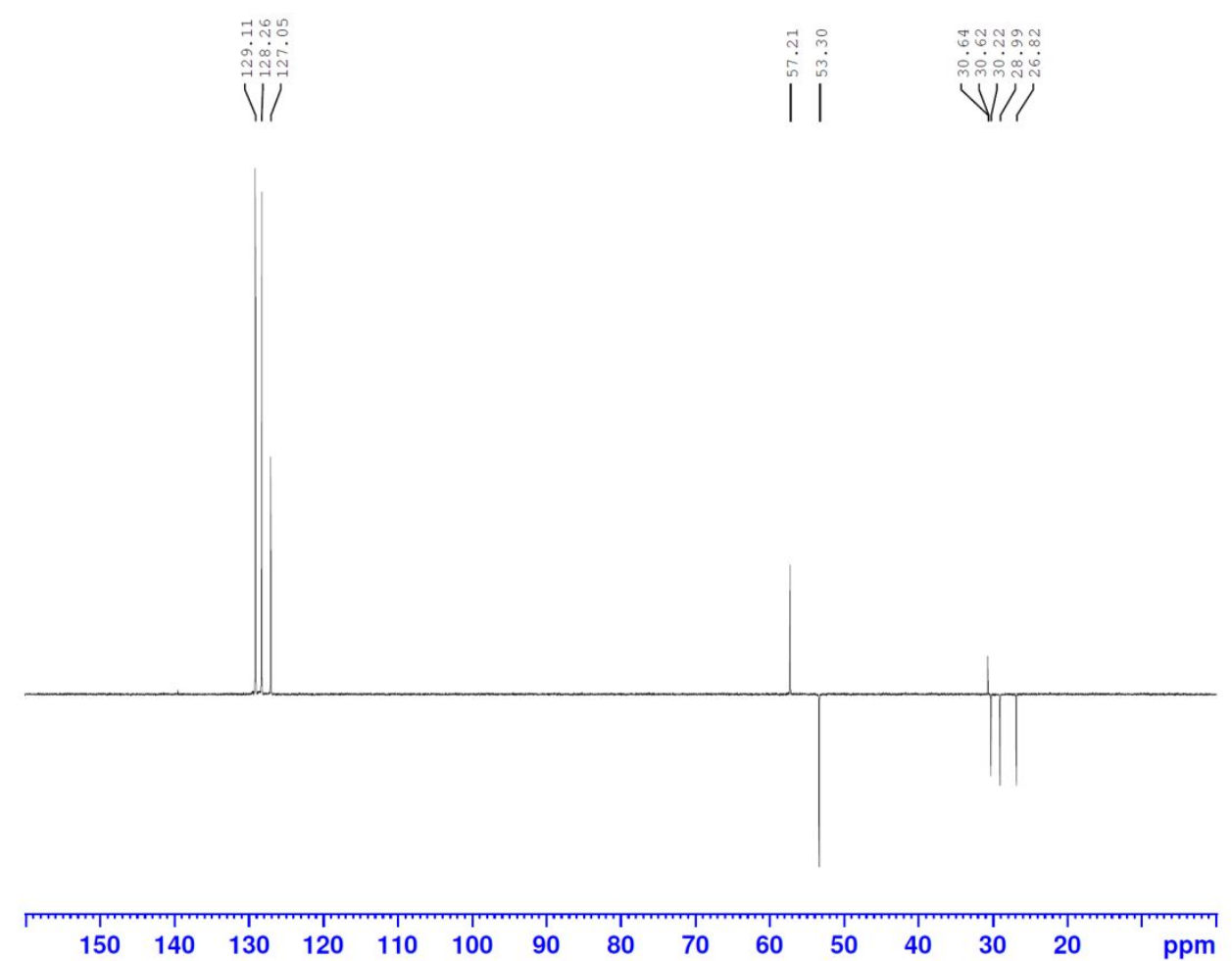

Figure S20. 2D NMR HSQC for 4




Figure S21. 2D NMR HMBC for 4

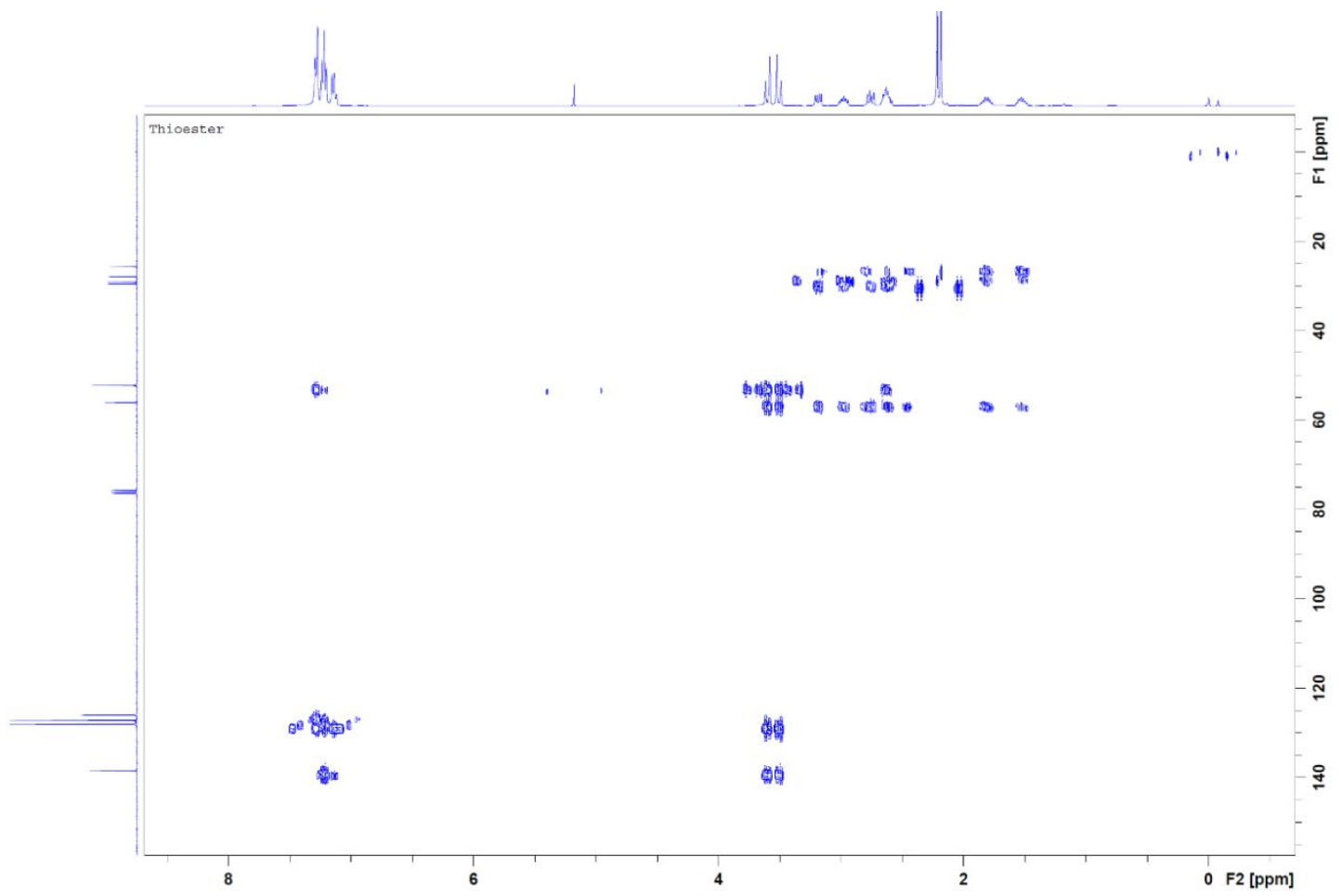

Figure S22: HPLC for Compound 1

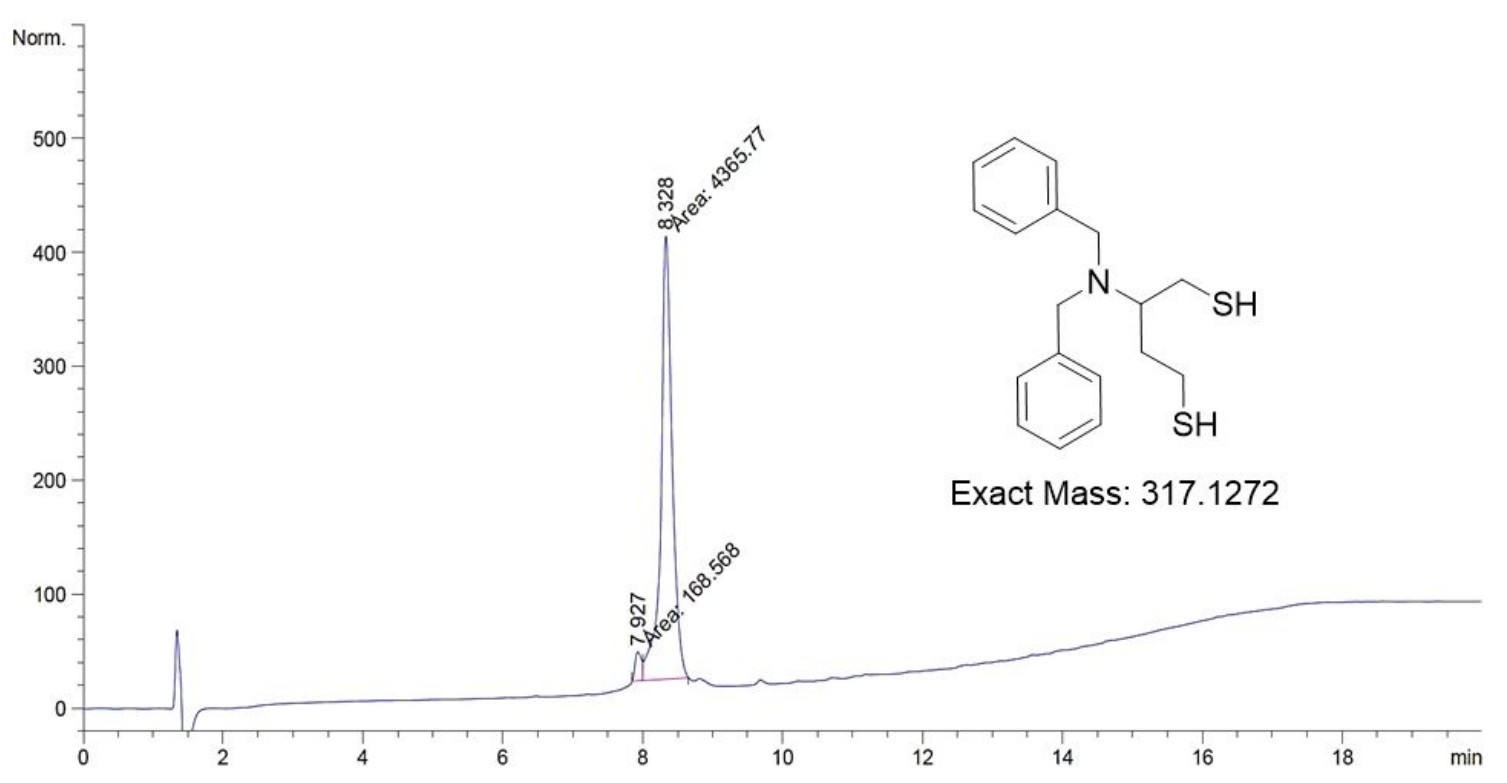


Figure S23. HRMS for compound 1



Figure S24. ${ }^{1} \mathrm{H}$ NMR for 1

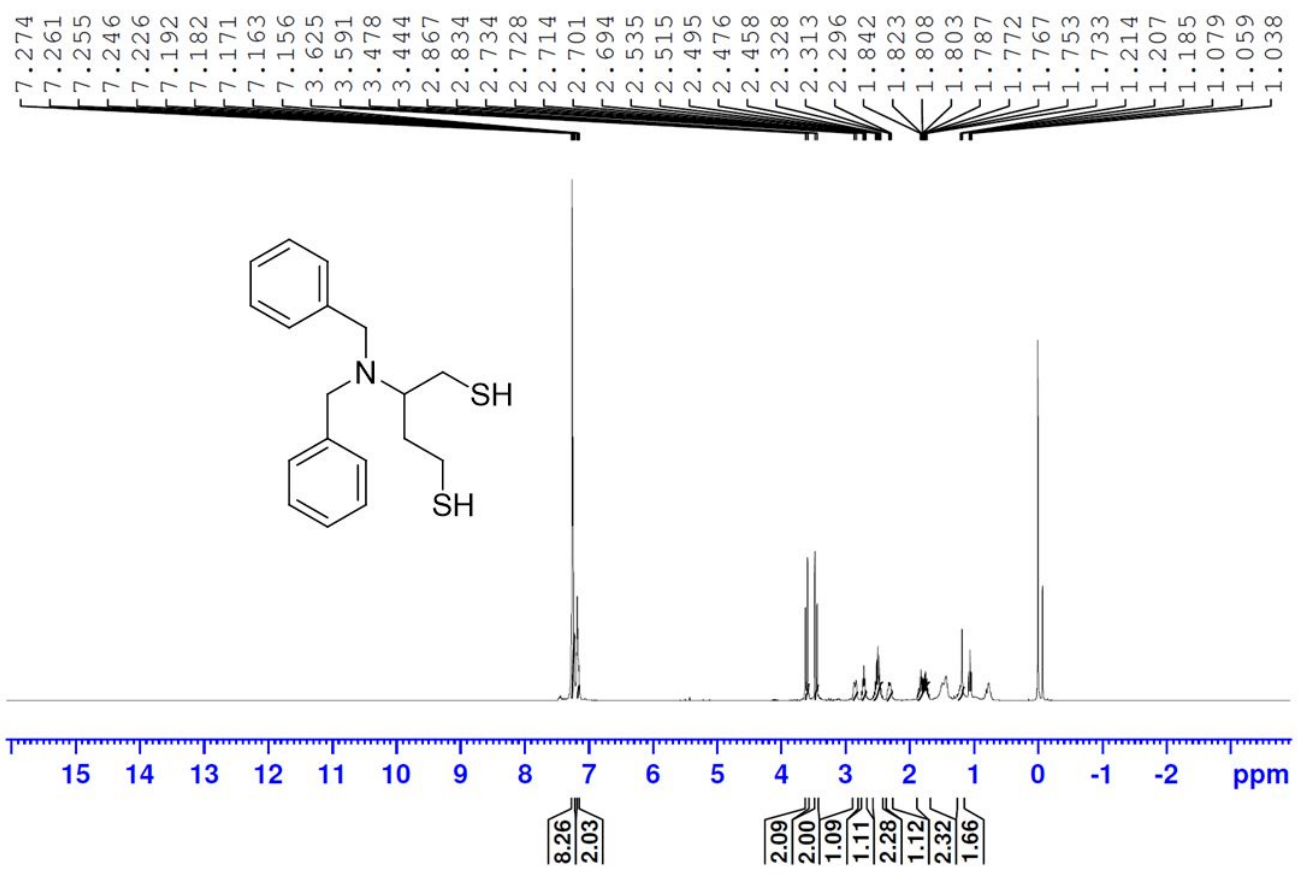


Figure S25. ${ }^{13} \mathrm{C}$ NMR for $\mathbf{1}$

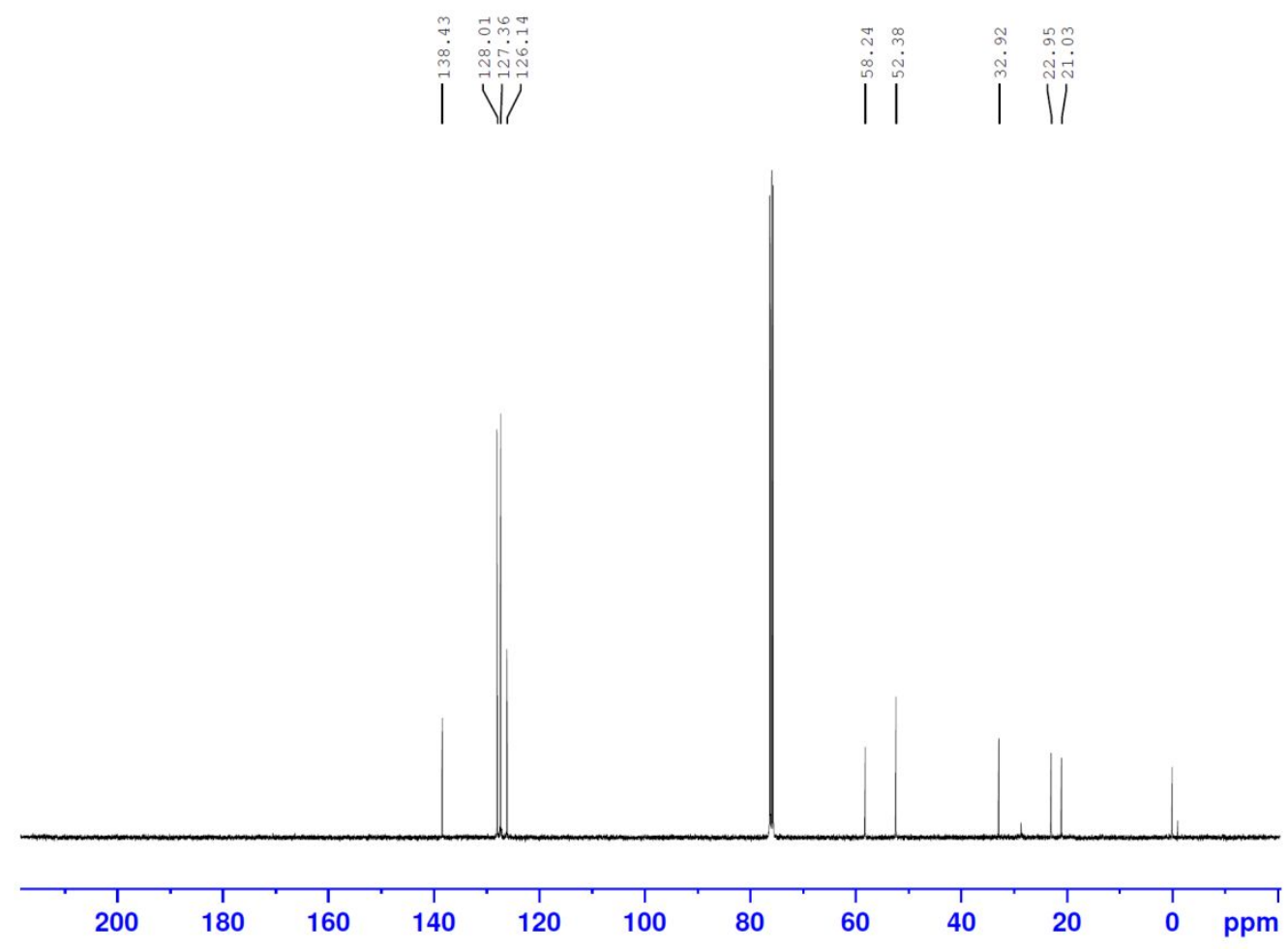

Figure S26. ${ }^{13} \mathrm{C}$ DEPT 135 for $\mathbf{1}$

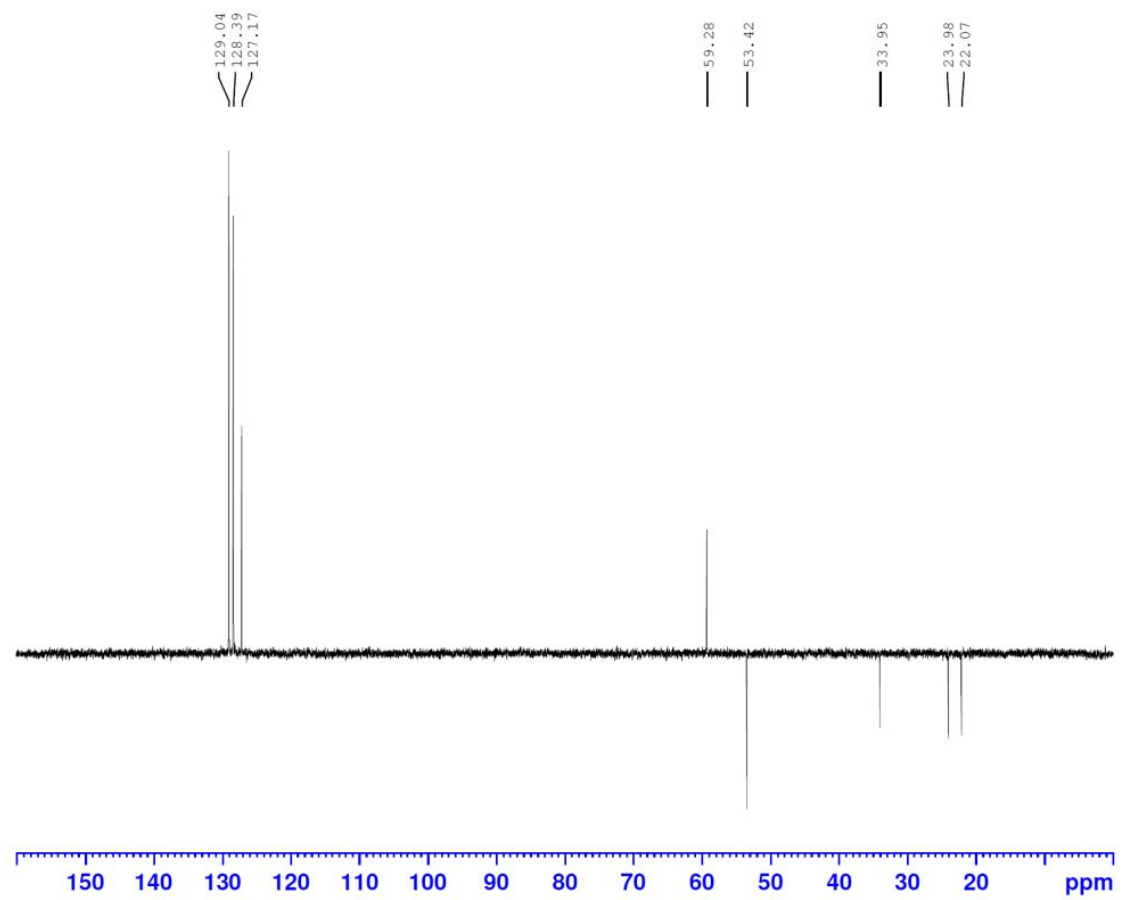


Figure S27. 2D NMR HSQC for 1

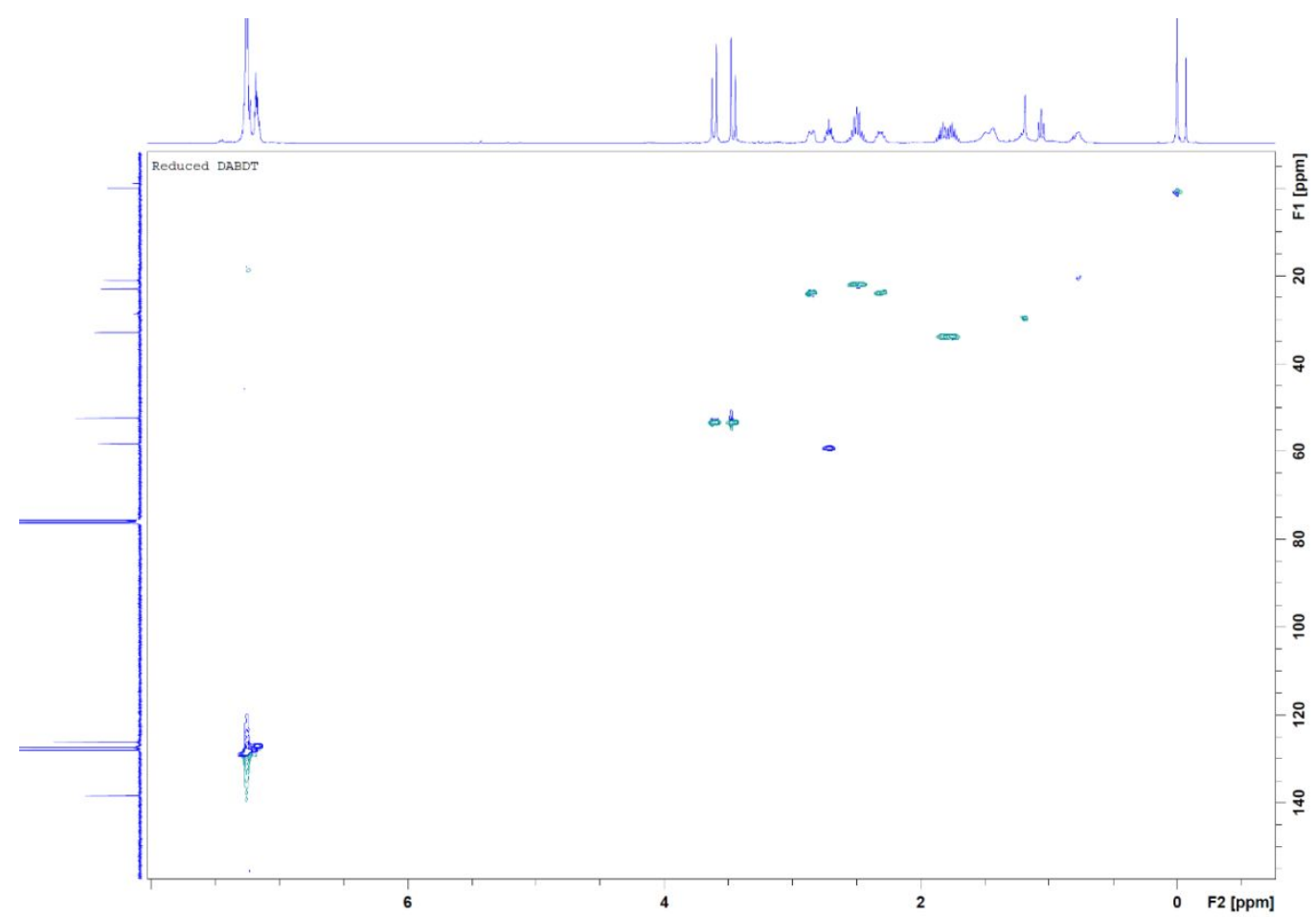

Figure S28. 2D NMR HMBC for 1

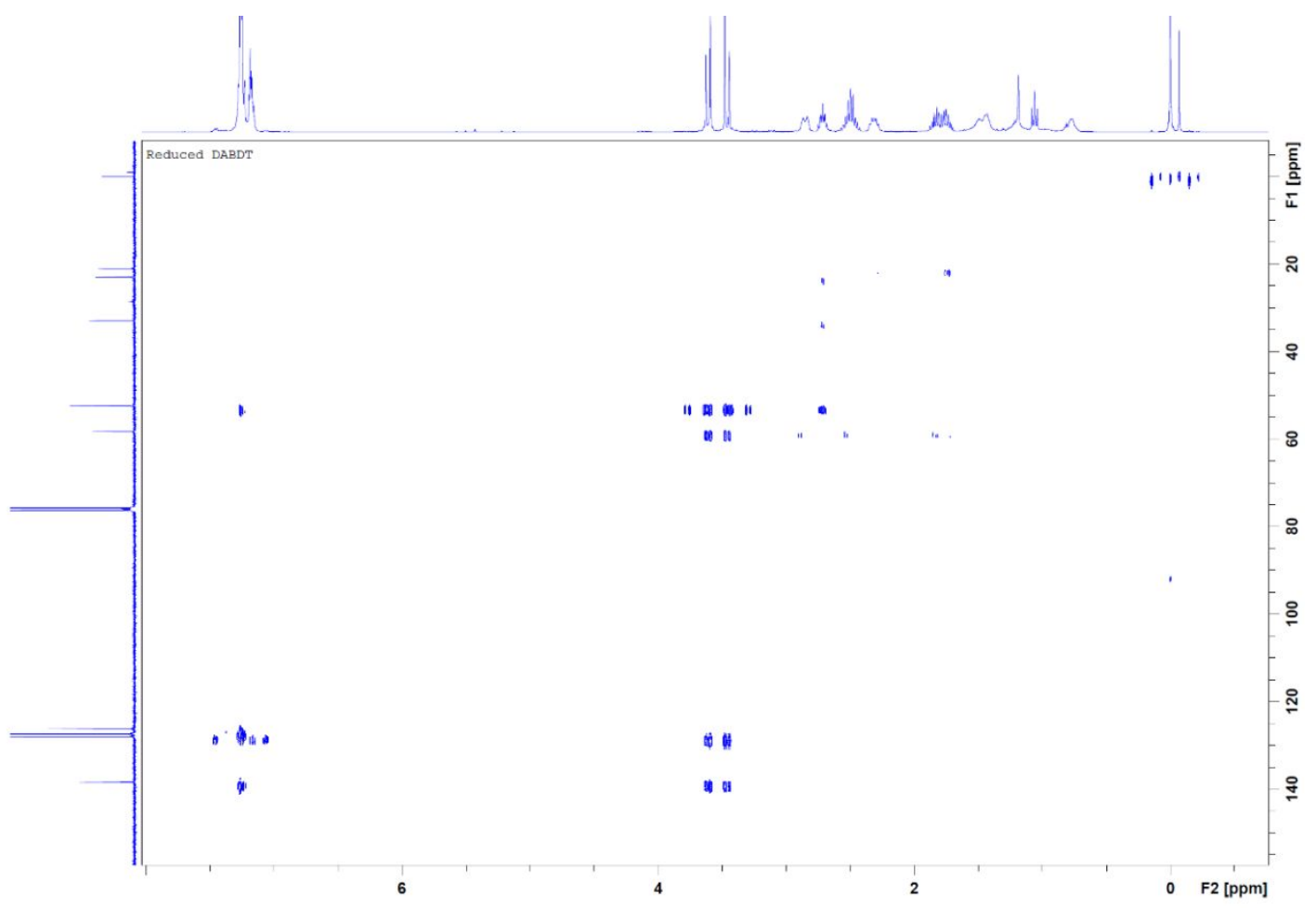


Figure S29. HPLC for $\mathbf{1}^{\text {xx }}$



Figure S30. HRMS for $\mathbf{1}^{\text {ox }}$

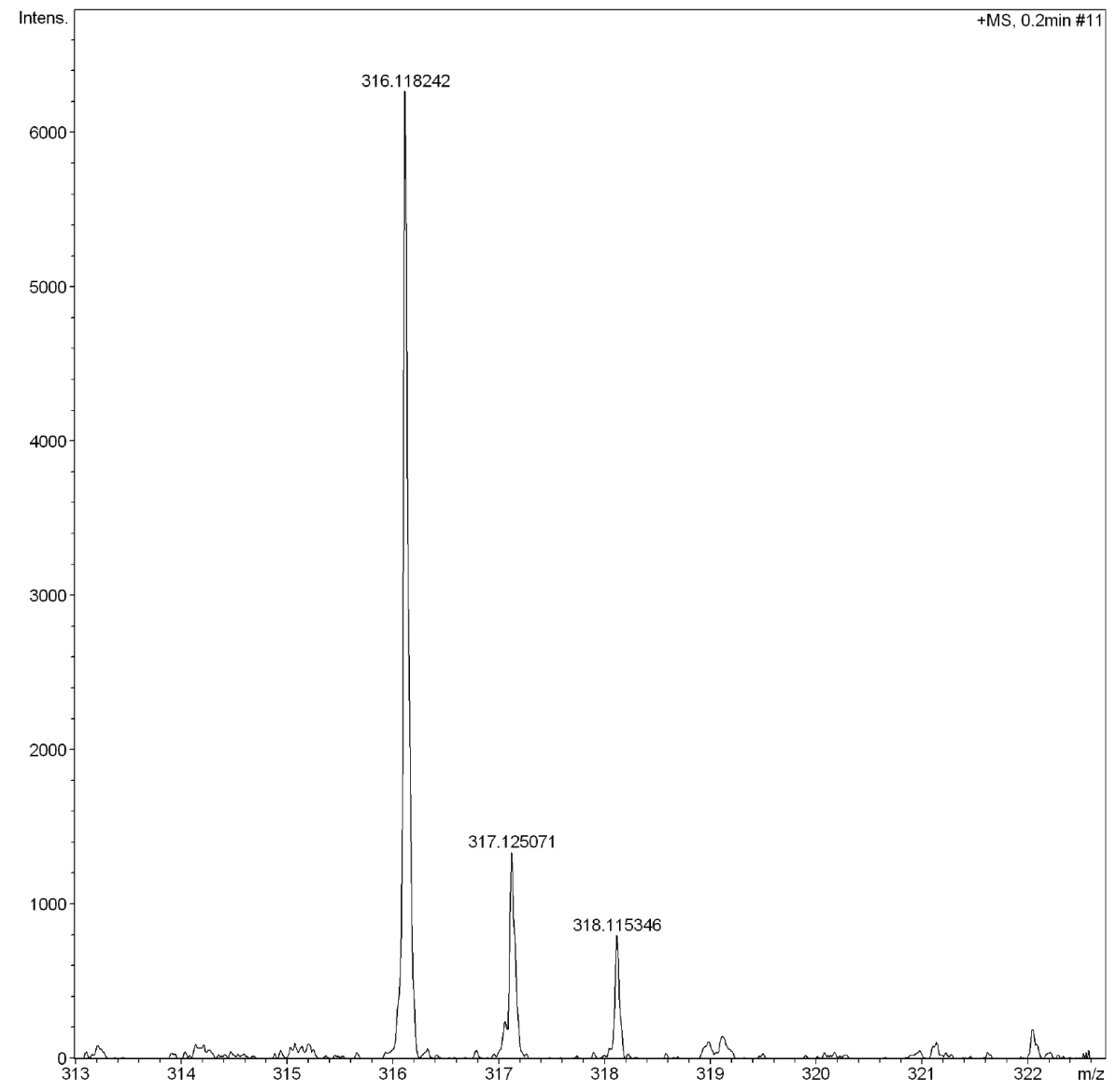


Figure S31. ${ }^{1} \mathrm{H}$ NMR for $\mathbf{1}^{\text {ox }}$

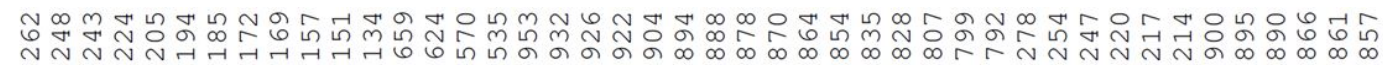



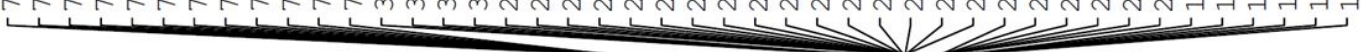

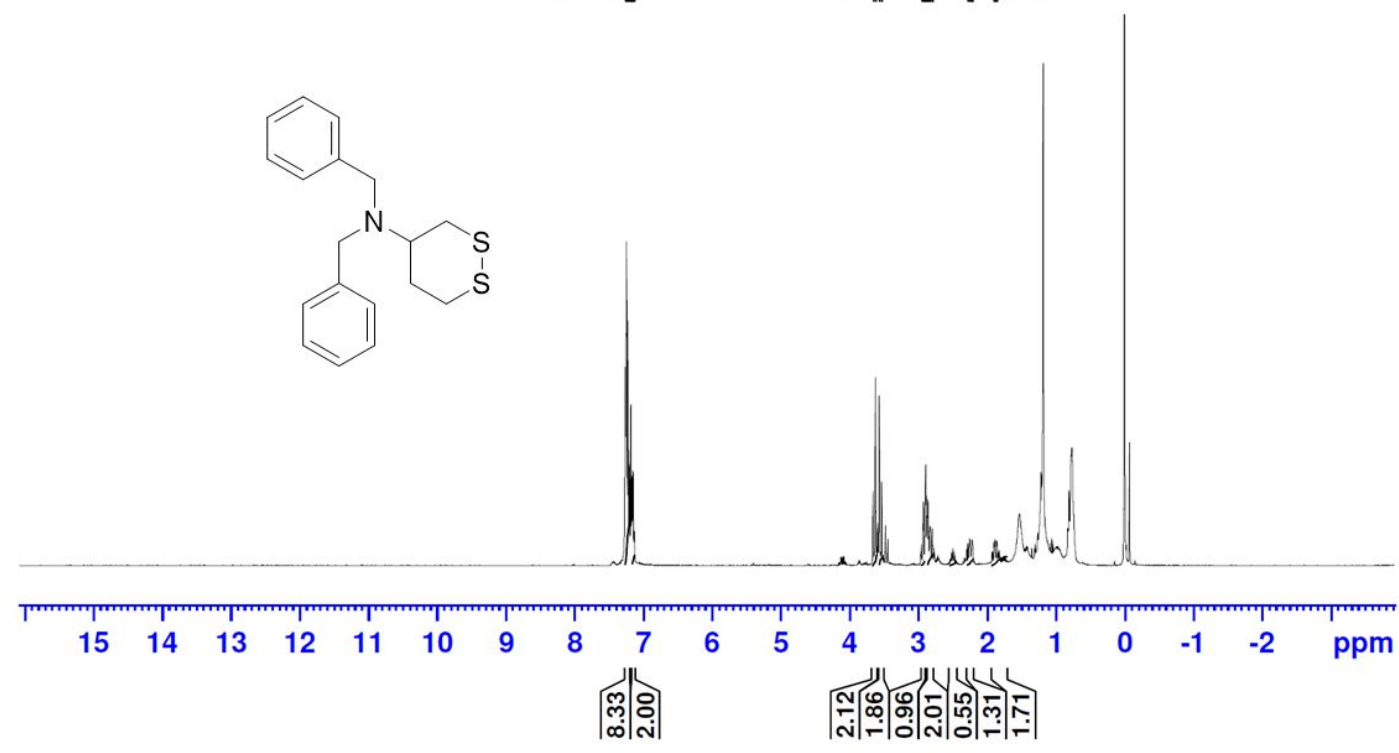

Figure S32. ${ }^{13} \mathrm{C}$ NMR for $\mathbf{1}^{\text {ox }}$




Figure S33. ${ }^{13} \mathrm{C}$ DEPT 135 for $\mathbf{1}^{\text {ox }}$



Figure S34. 2D NMR HSQC for $\mathbf{1}^{\mathrm{ox}}$

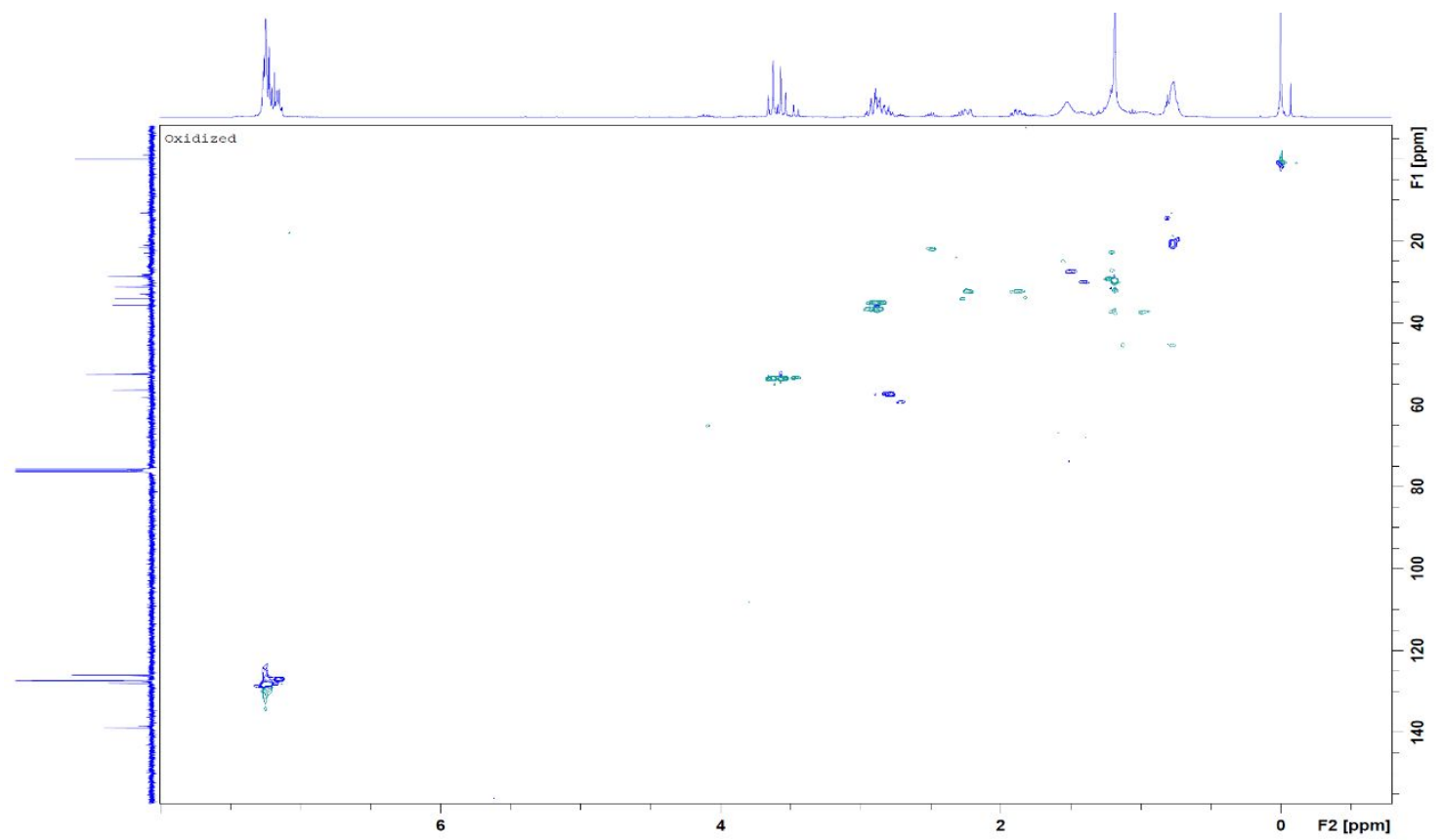


Figure S35. 2D NMR HMBC for $\mathbf{1}^{\mathbf{0 x}}$

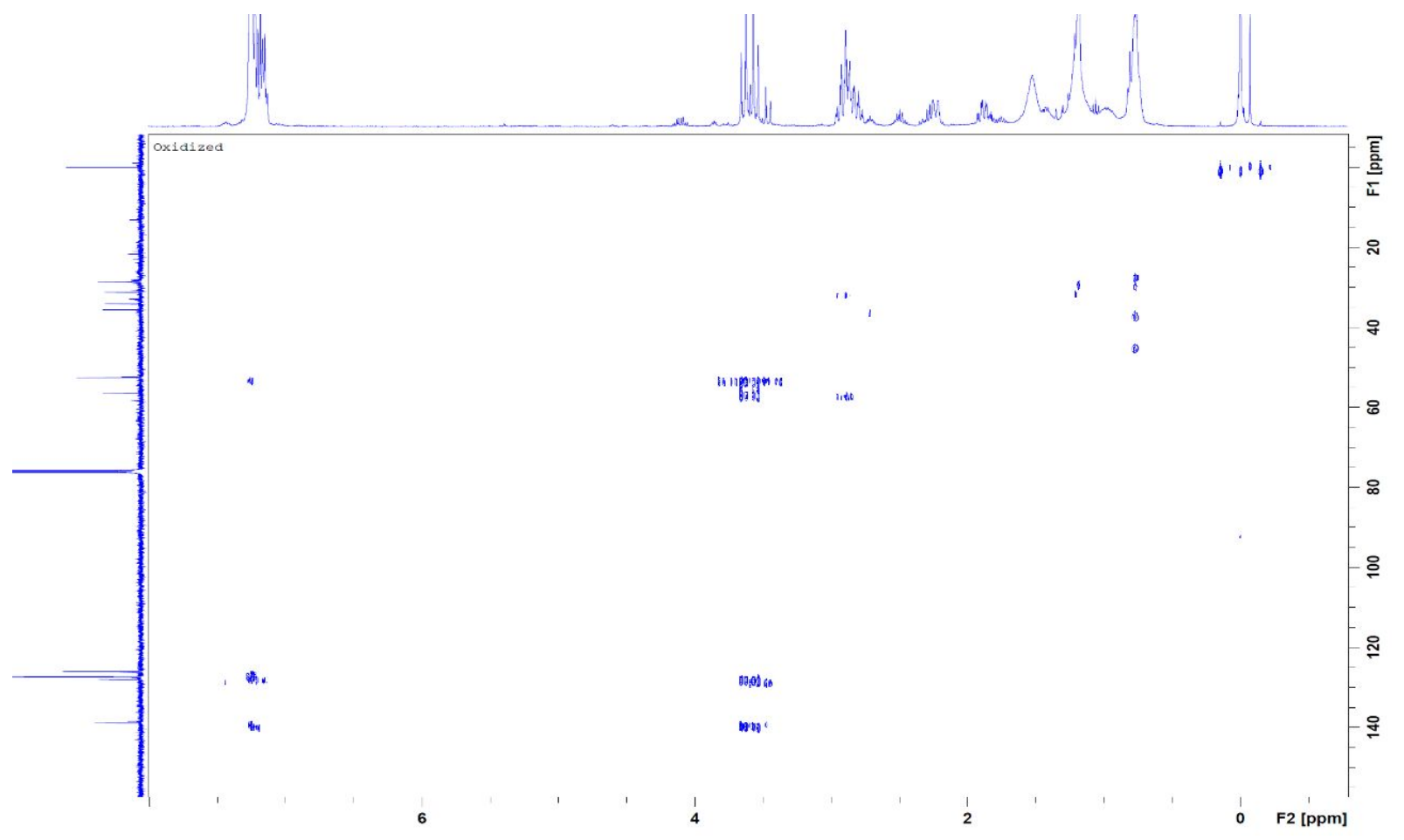

Figure S36: Fmoc-Cys(SDMP)-OH




Figure S37: Fmoc-Cys(SDMP)-OH with DABDT with no water (0 min, $20 \mathrm{~min}, 40 \mathrm{~min}$ and $80 \mathrm{~min})$.
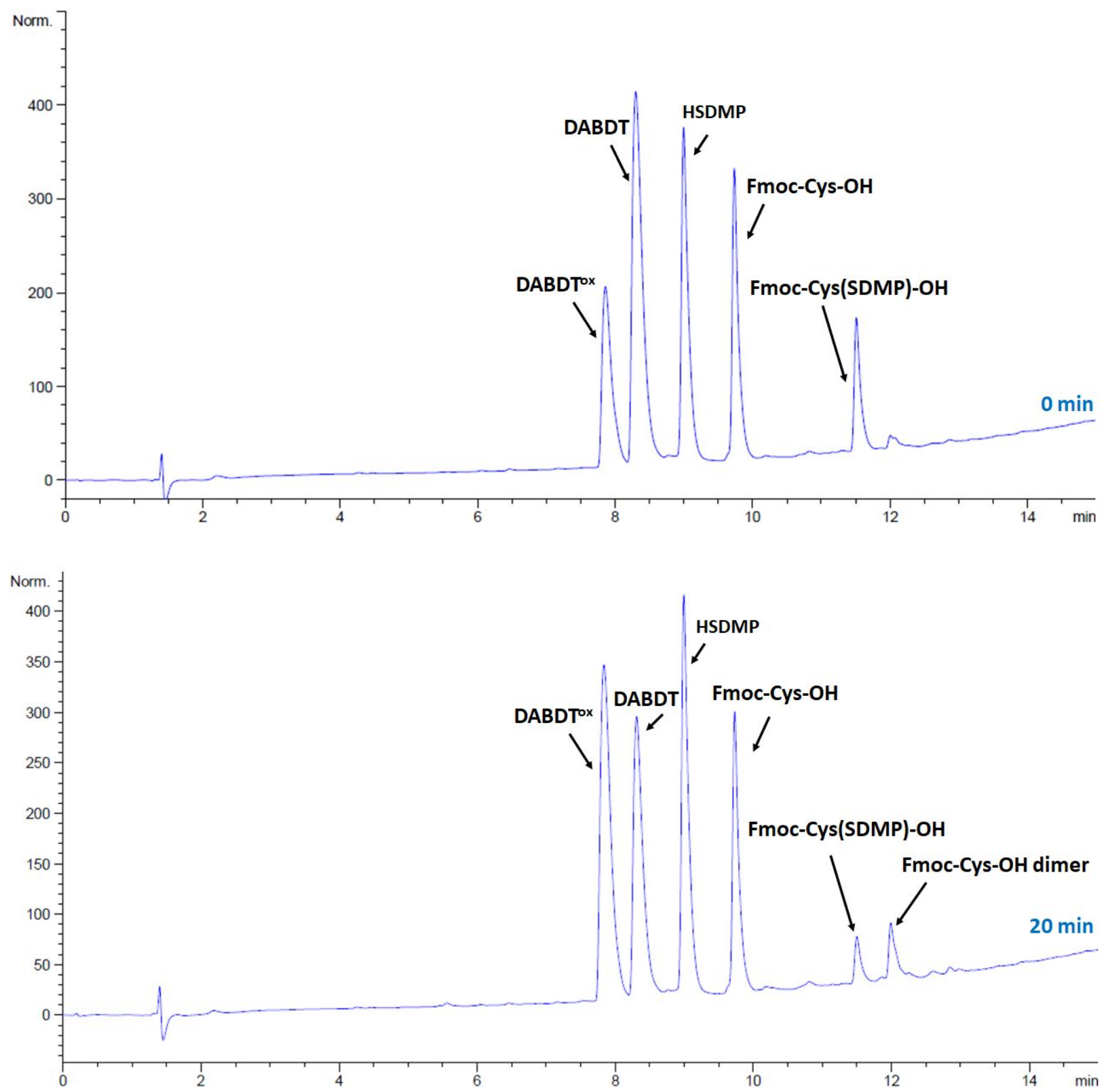

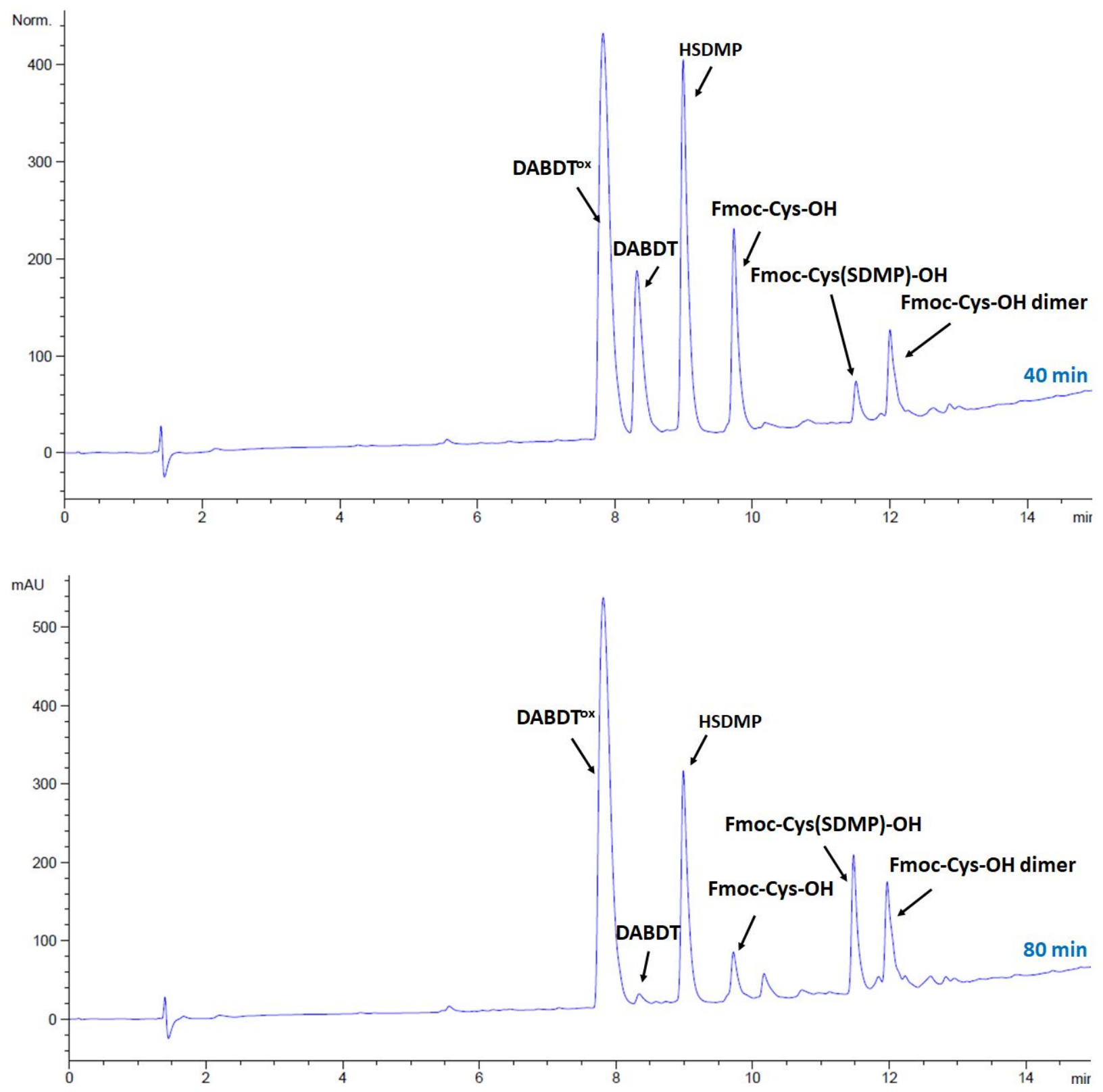
Figure S38: Fmoc-Cys(SDMP)-OH with DABDT (1:1, 1:3 and 1:5 ratio) with 3\% water in 0 min
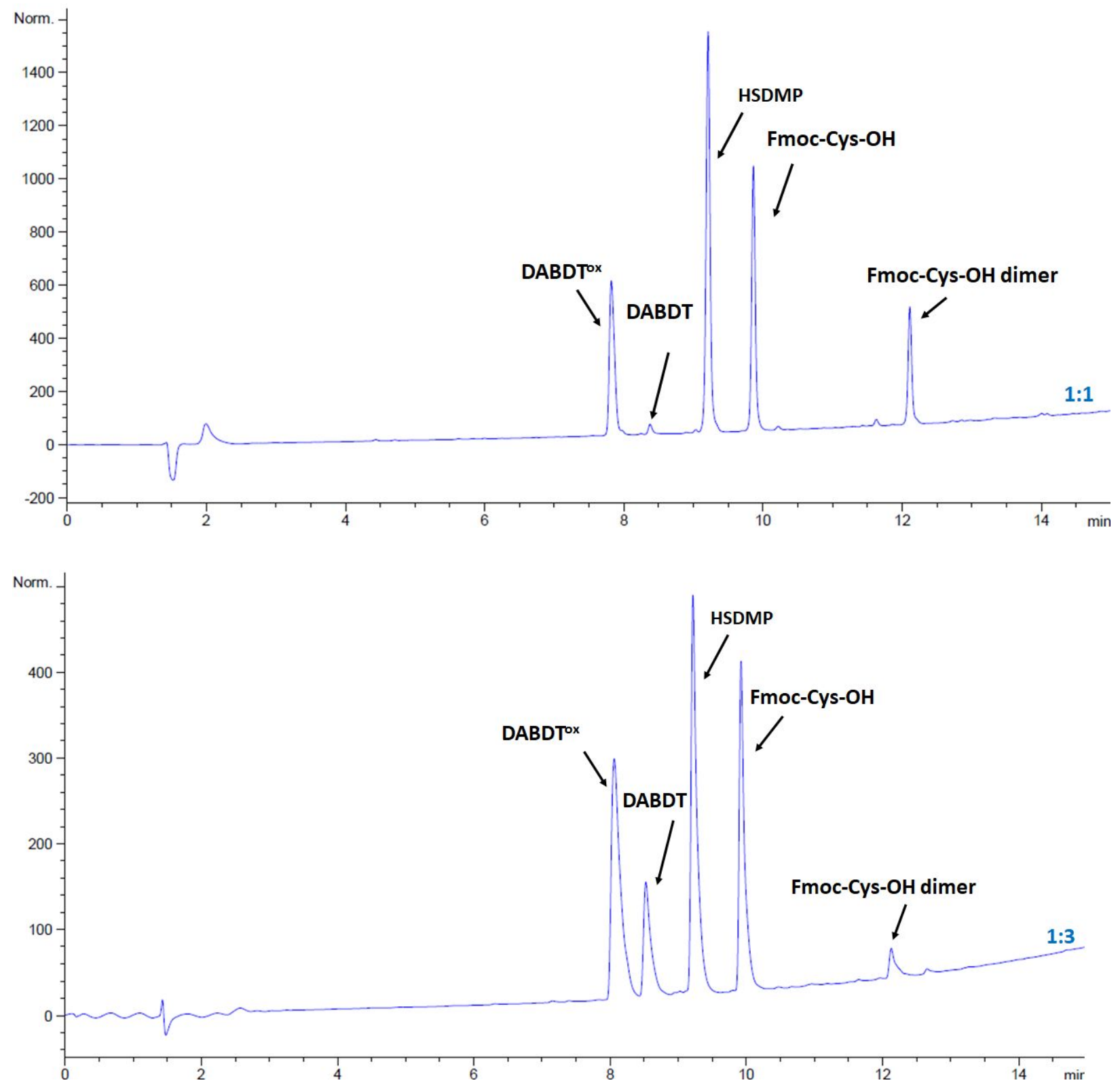


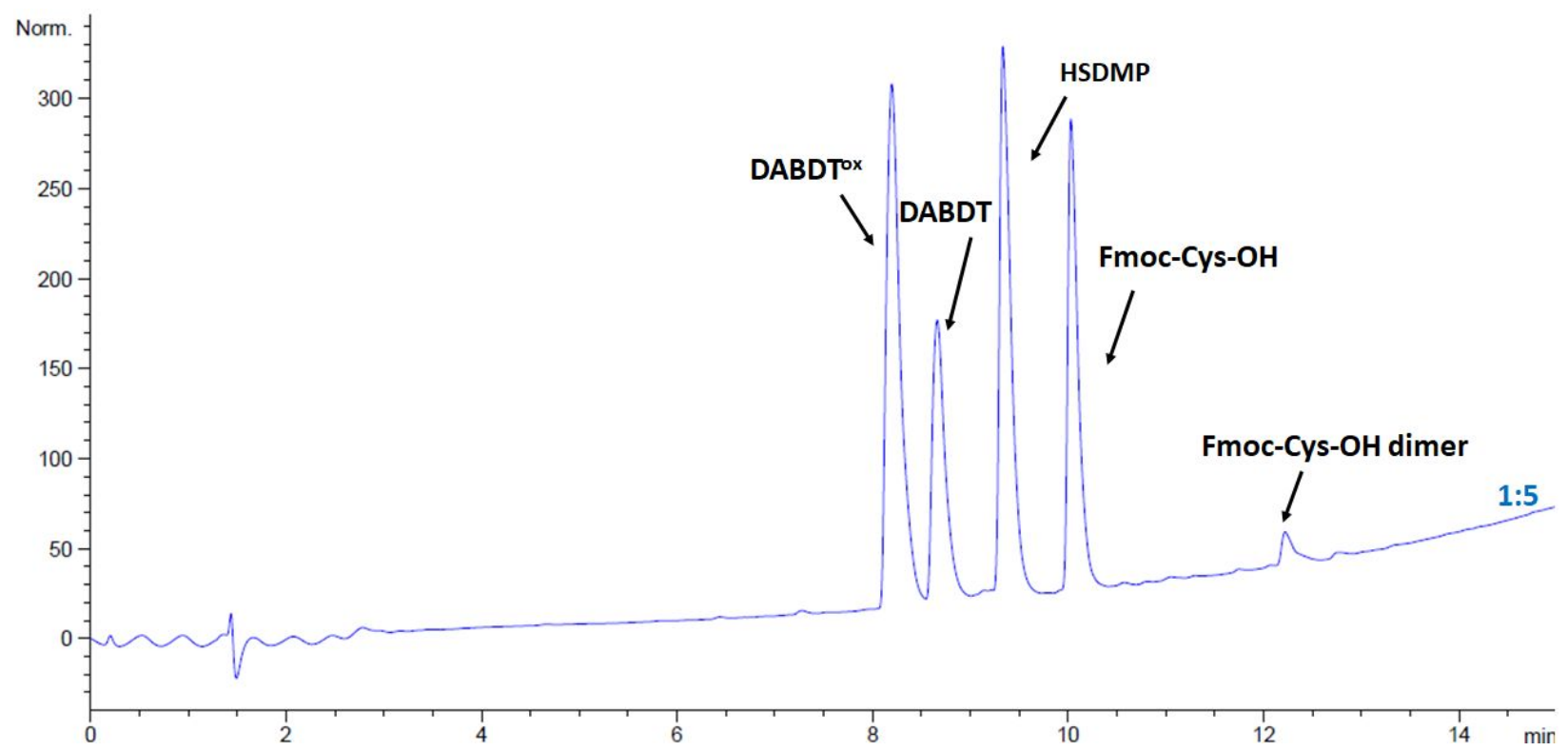

Figure S39: Fmoc-Cys(SDMP)-OH with DABDT (1:1, 1:3 and 1:5 ratio) with 3\% $\mathrm{MeOH}$ in 0 min

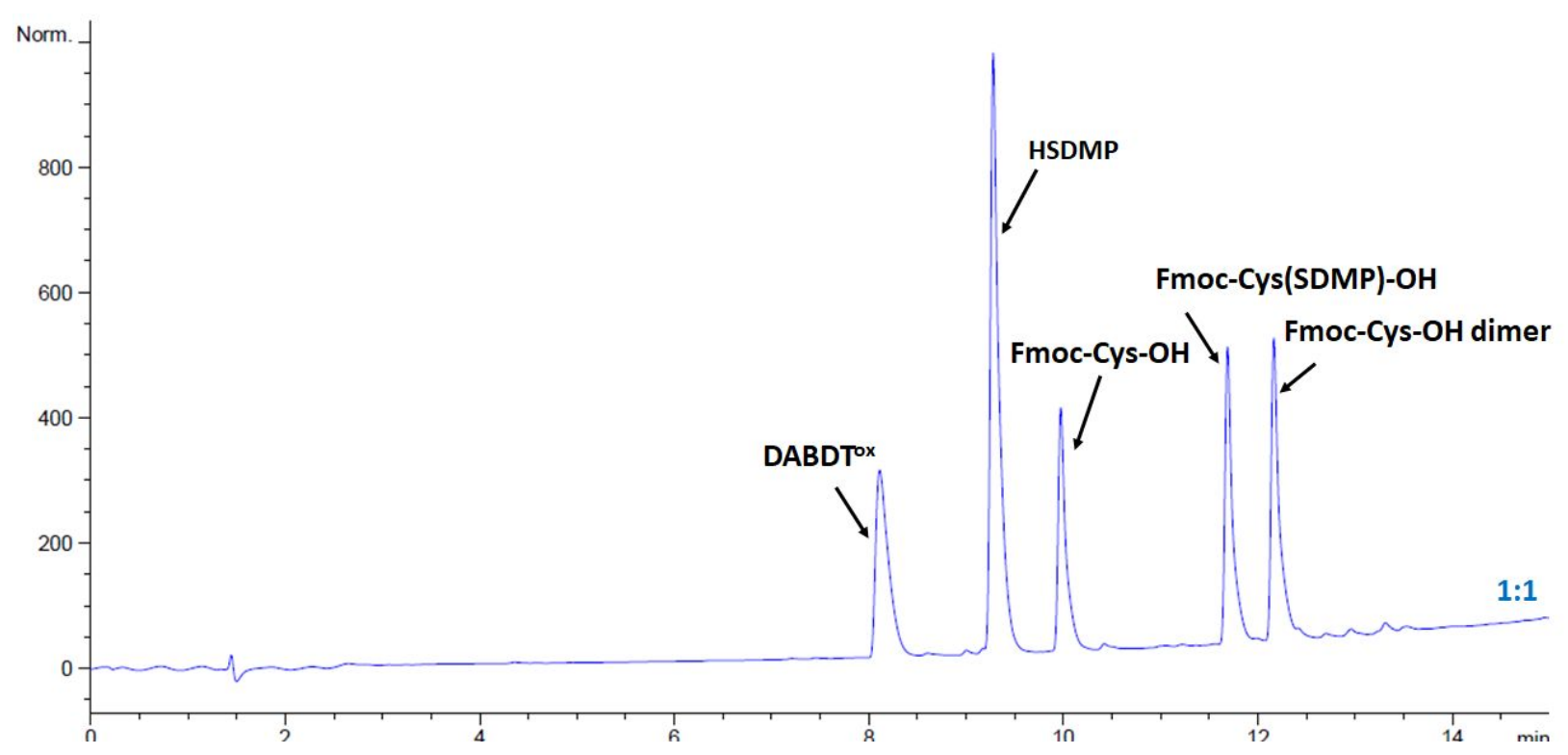



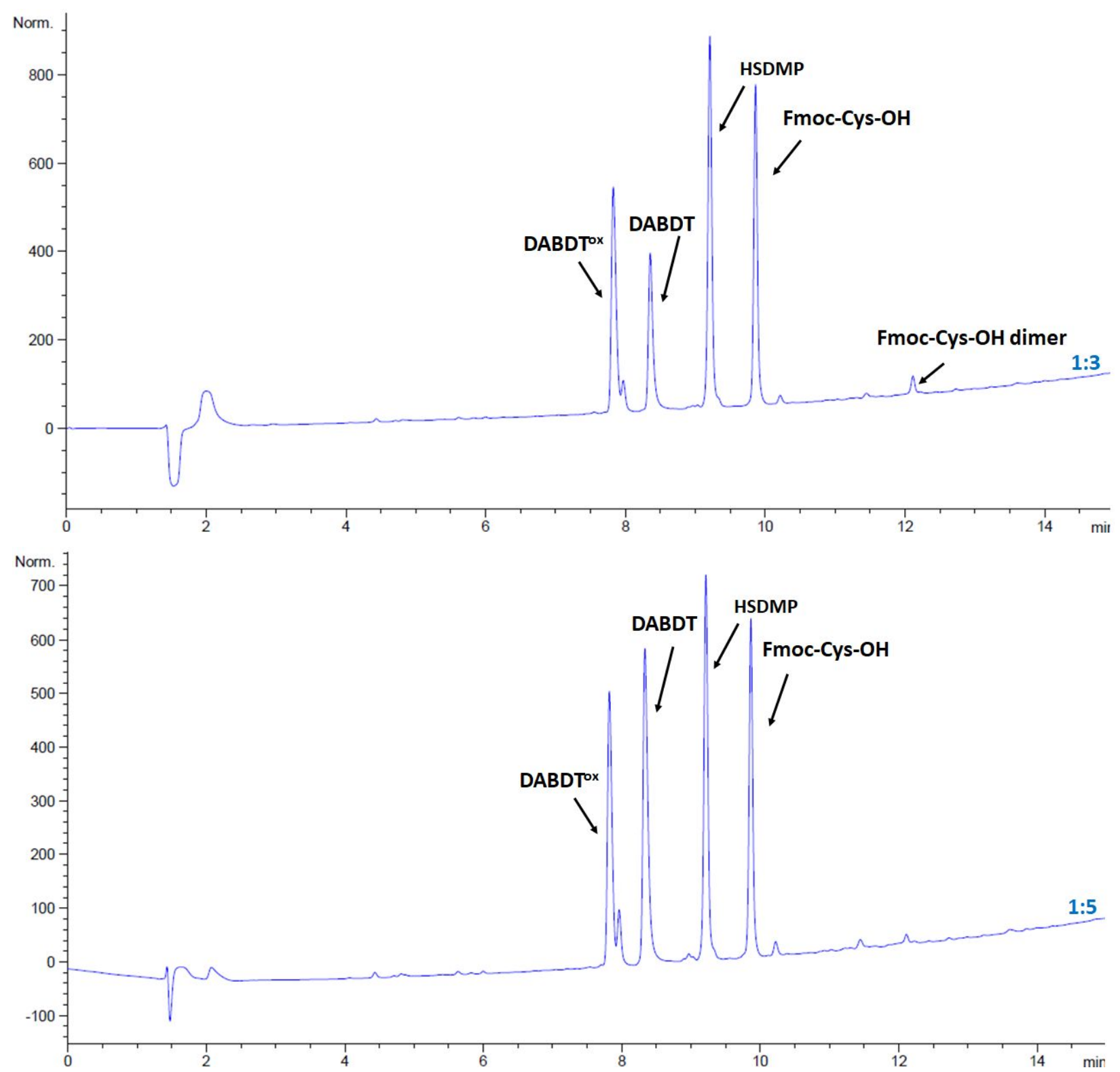
Figure S40: Fmoc-C(SDMP)GFL-NH $\mathrm{NH}_{2}$



Figure S41: Fmoc-C(SDMP)GFL-resin with DABDT with 3\% water in DMF

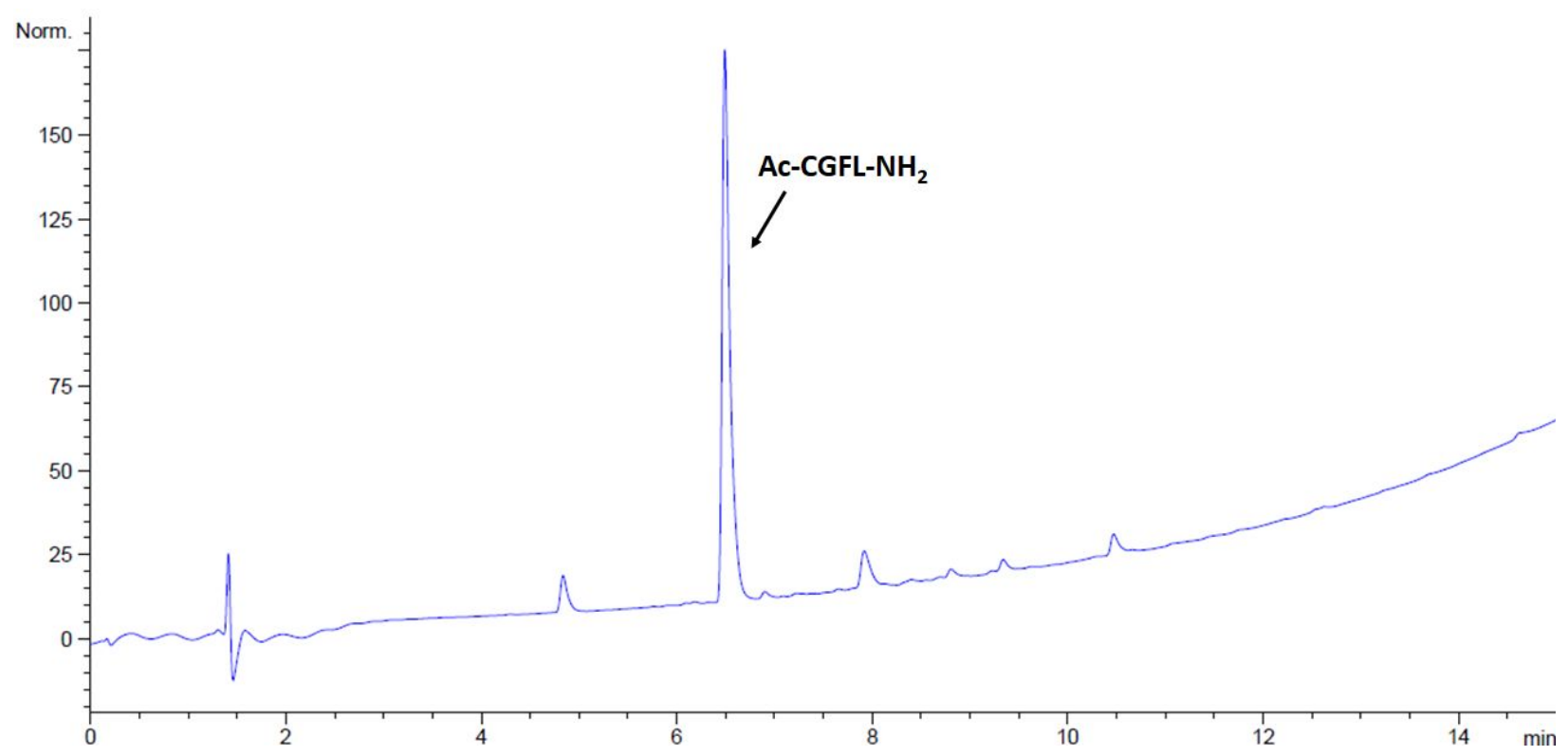


Figure S42: DTDP-GFL-NH

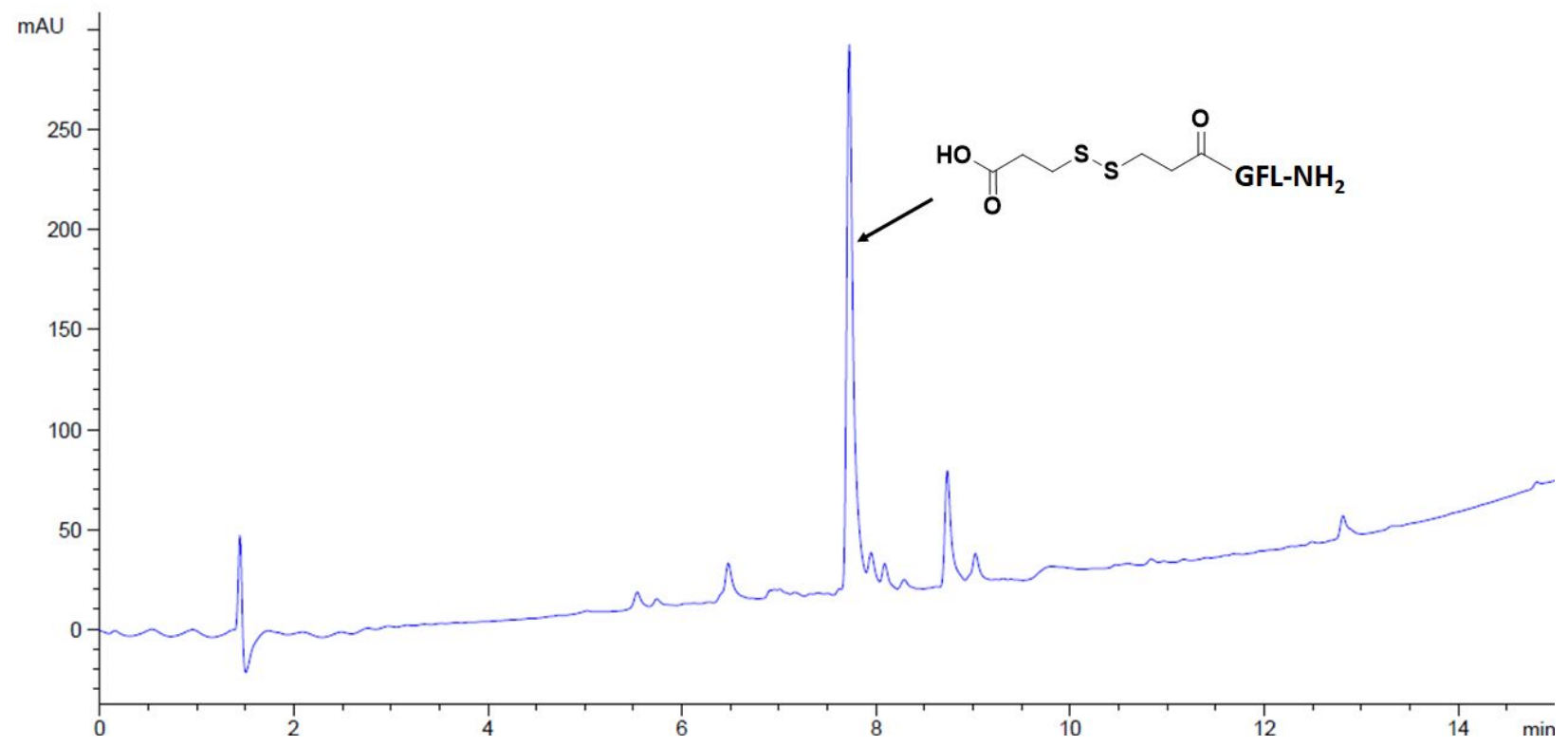

Figure S43: DTDP-GFL-resin with DABDT with 3\% water in DMF

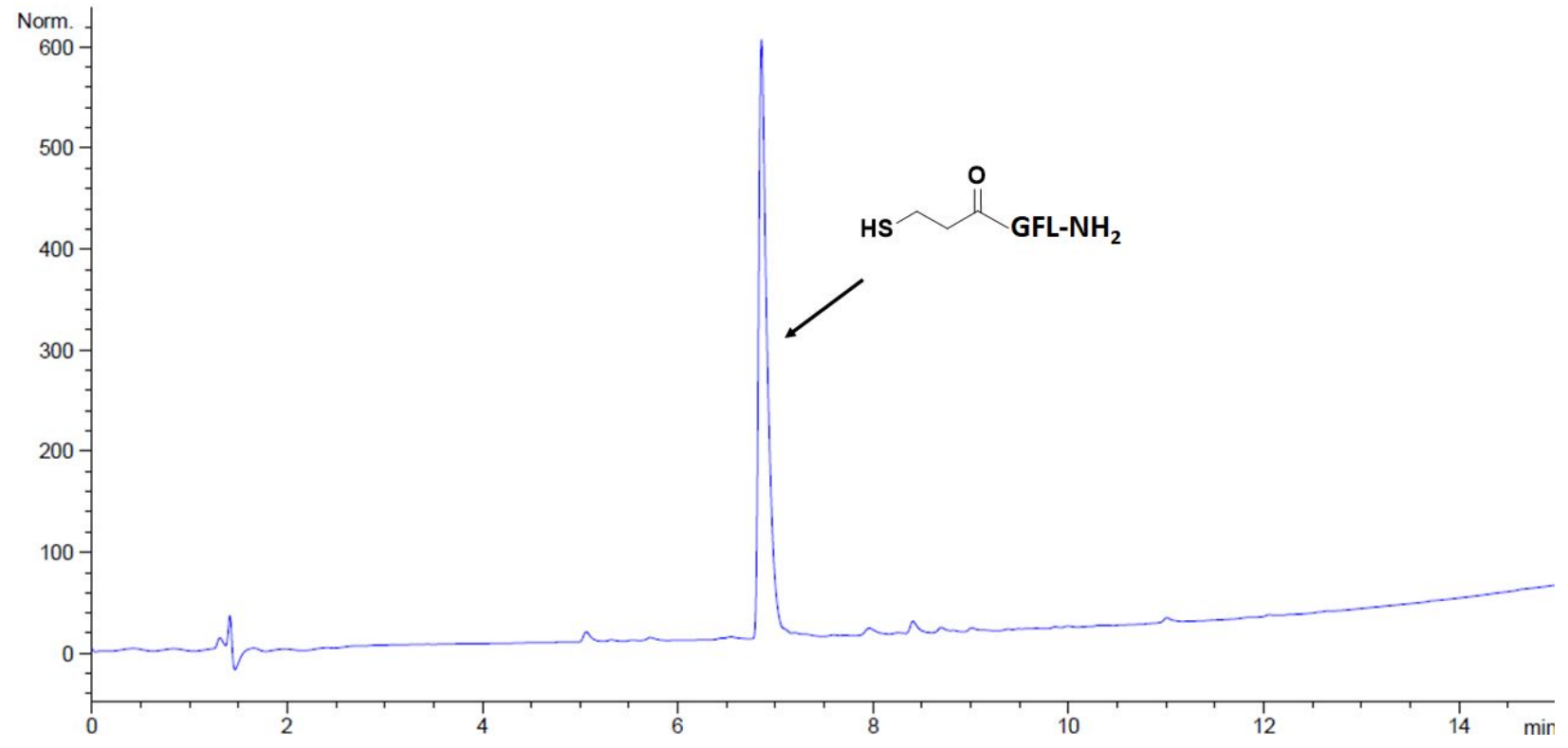


Figure S44: Fmoc-AC(SDMP)L-NH ${ }_{2}$

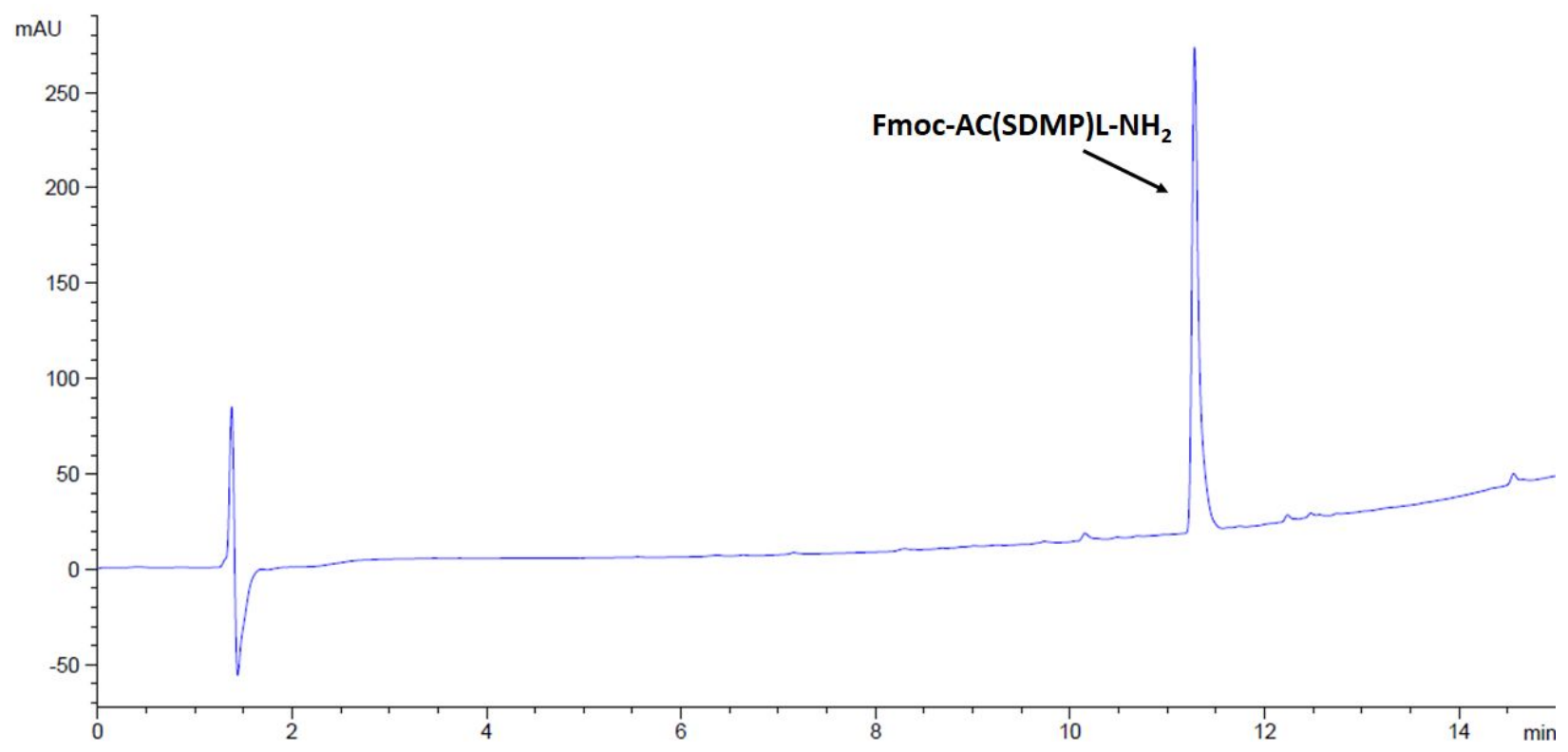

Figure S45: Fmoc-AC(SDMP)L-resin with DABDT with 3\% water in DMF




Figure S46: Fmoc-N-C(SDMP)-N-NH

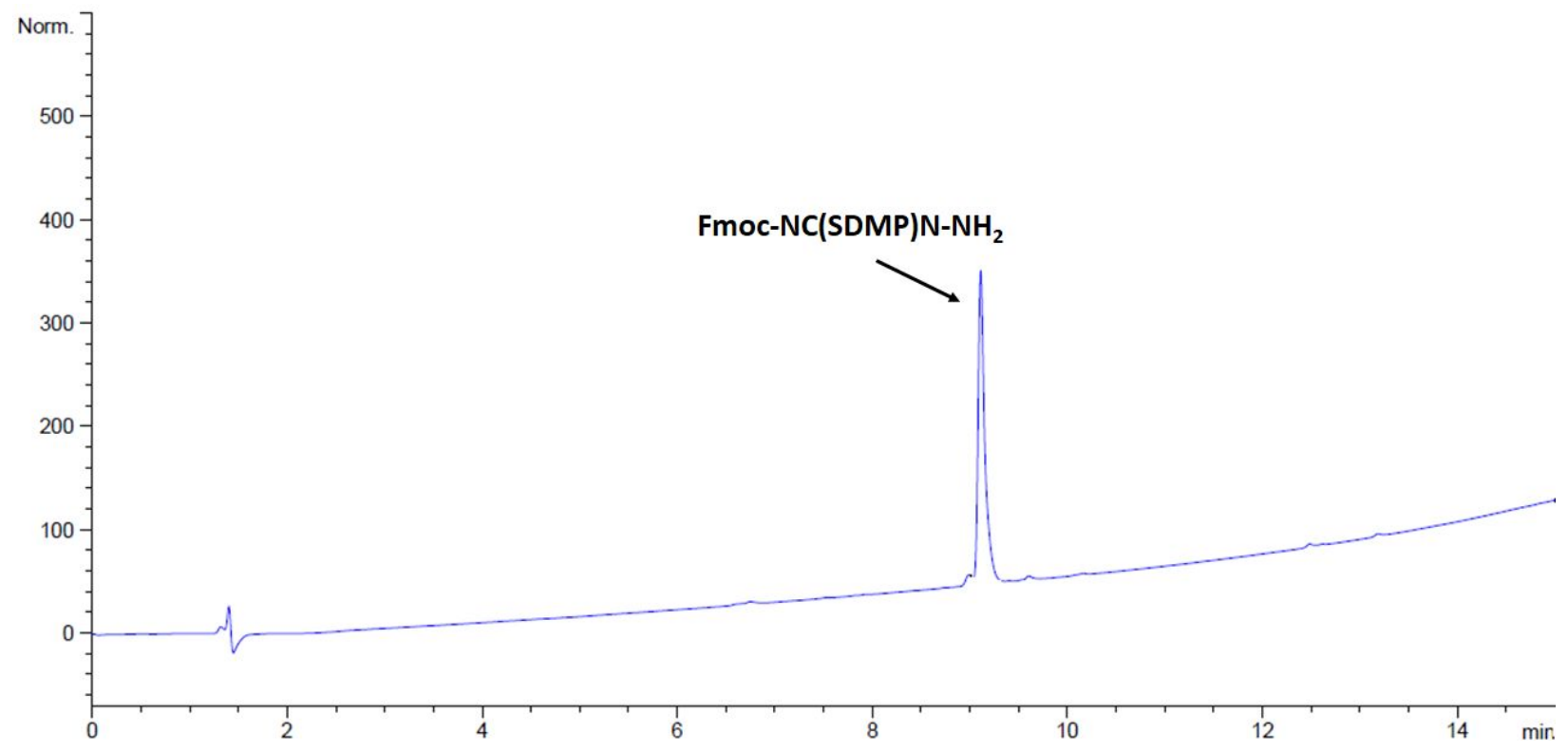

Figure S47: Fmoc-N(Trt)-C(SDMP)-N(Trt) -resin with DABDT with 3\% water in DMF

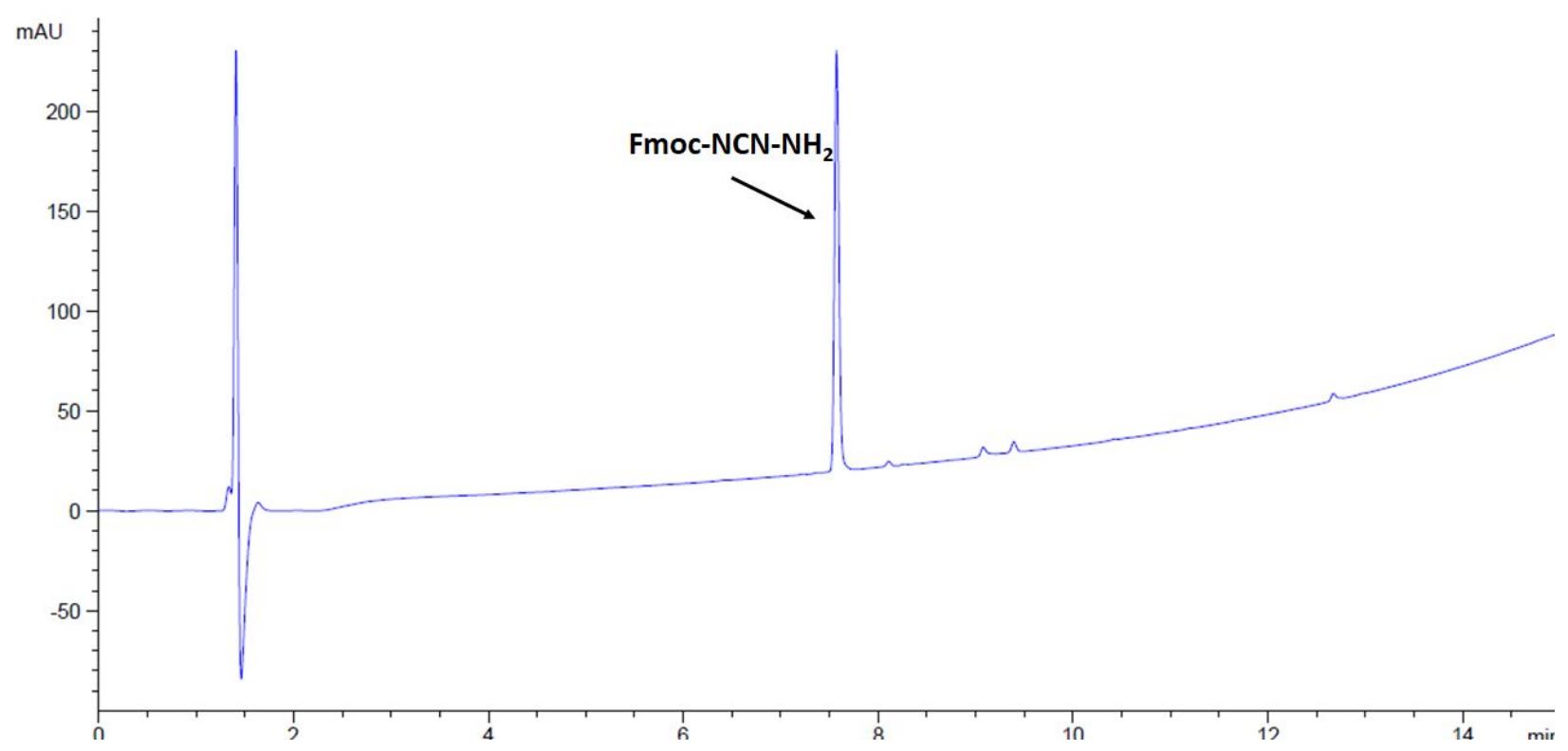


Figure S48: Fmoc-Oxytocin-resin with SDMP protection on Cys [FmocC(SDMP)YIQNC(SDMP)PLG-NH

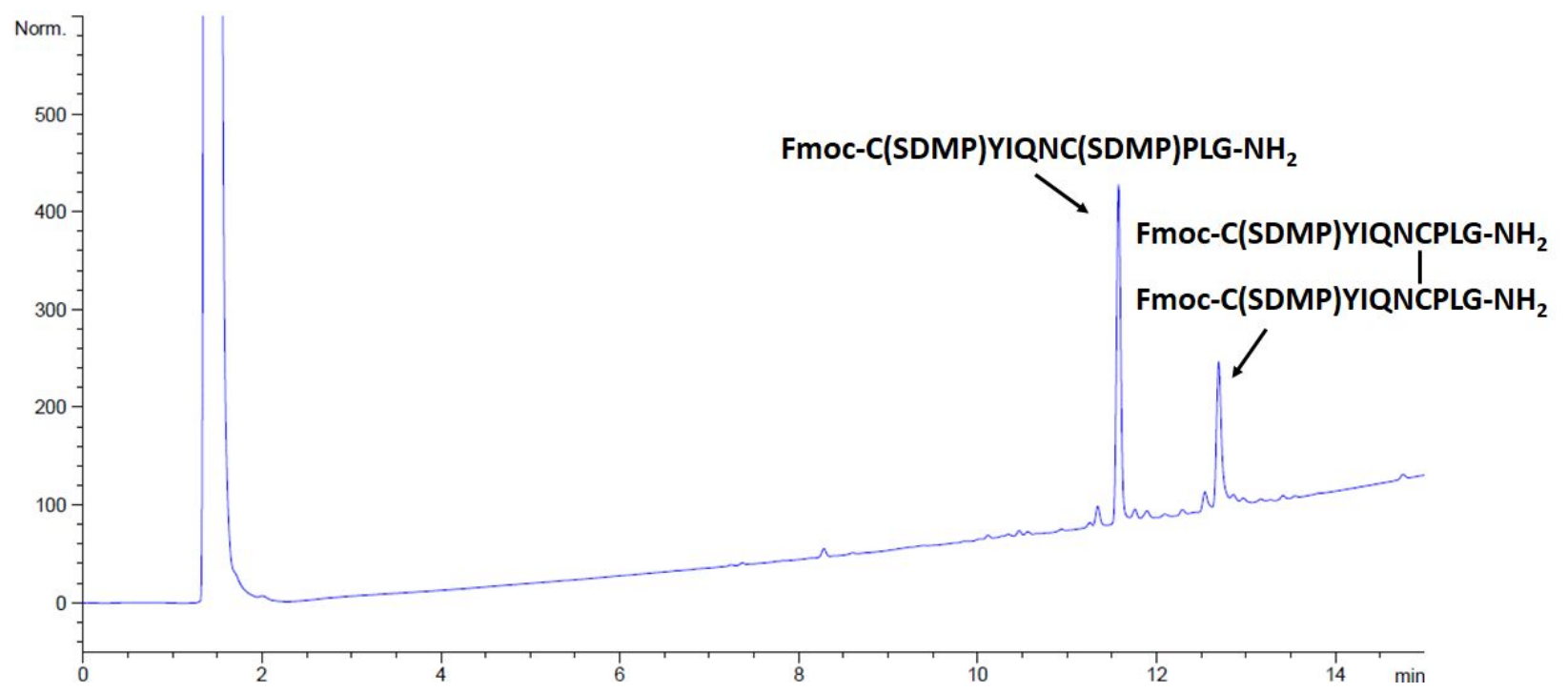

Figure S49: Fmoc-Oxytocin-resin with SDMP protection on Cys [FmocC(SDMP)YIQNC(SDMP)PLG-NH ${ }_{2}$ s synthesized with Fmoc-Cys(SDMP)-OH with DABDT with 3\% water in DMF

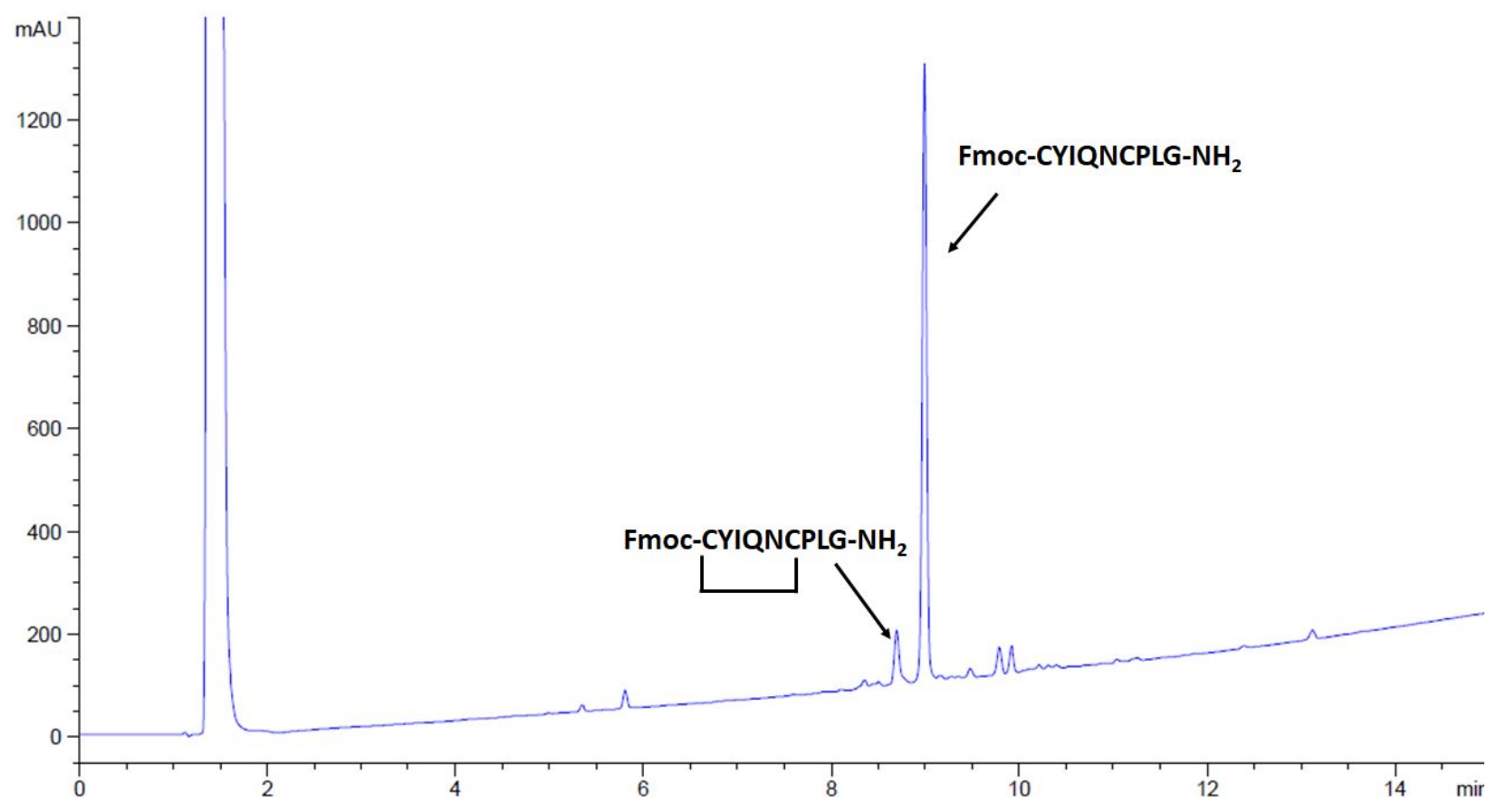


Figure S50: Fmoc-Oxytocin-resin with SDMP protection on Cys [FmocC(SDMP)YIQNC(SDMP)PLG-NH ${ }_{2}$ synthesized with Fmoc-Cys(SDMP)-OH with DTT with 3\% water in DMF

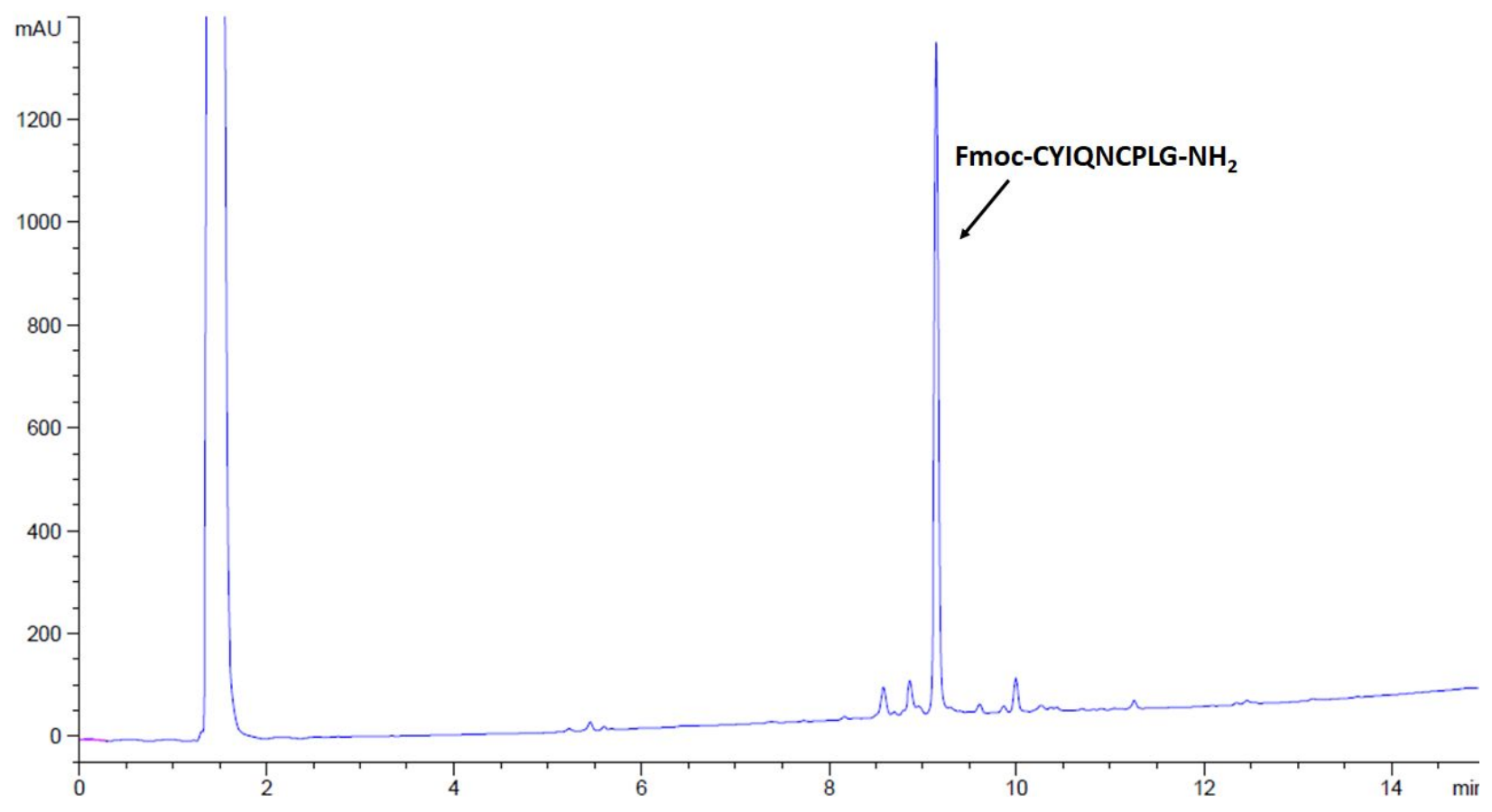

